Final Report

\title{
AN INNOVATIVE INTEGRATED APPROACH TO MINIMIZING GYPSUM AND PYRITE WASTES BY CONVERSION TO MARKETABLE PRODUCTS
}

U.S. Contract No. DE-FG26-98FT40114--01

\author{
Submitted to
}

\author{
U.S. Department of Energy \\ National Energy Technology Laboratory \\ P.O. Box 10940, MS FT-54 \\ Pittsburgh, PA 15236
}

\author{
From \\ University of Kentucky \\ Center for Applied Energy Research \\ 2540 Research Park Drive \\ Lexington, KY 40511-8410
}

June 27, 2000 


\section{TABLE OF CONTENTS}

$\underline{\text { Page }}$

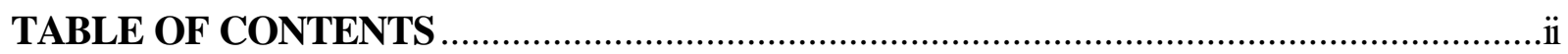

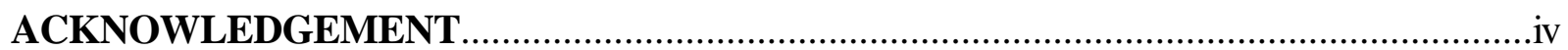

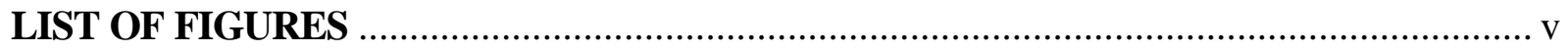

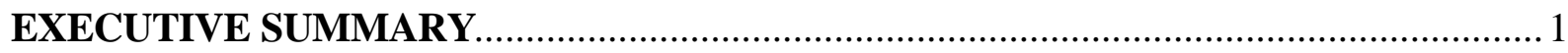

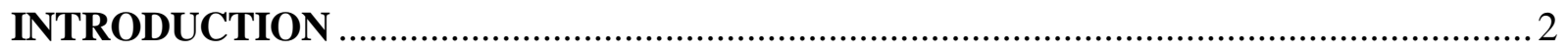

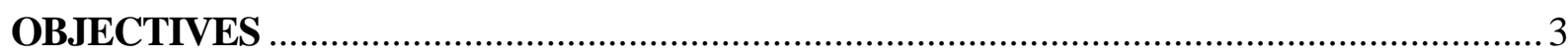

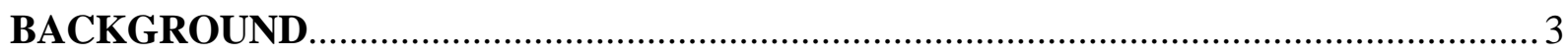

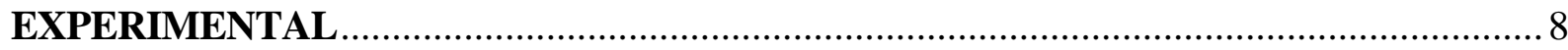

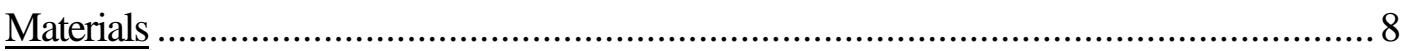

Instrumentation and Experimental Procedures............................................. 8

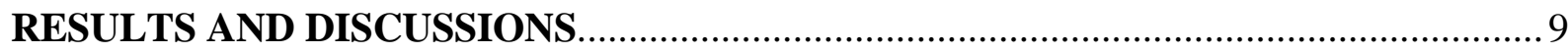

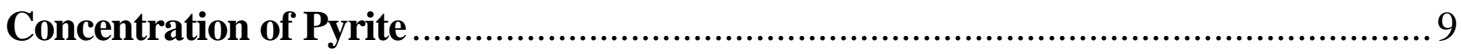

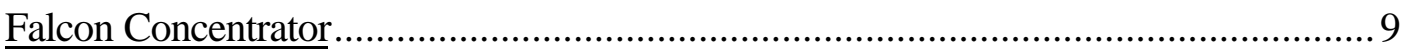

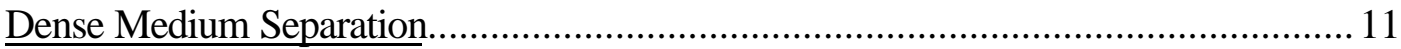

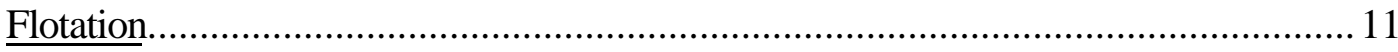

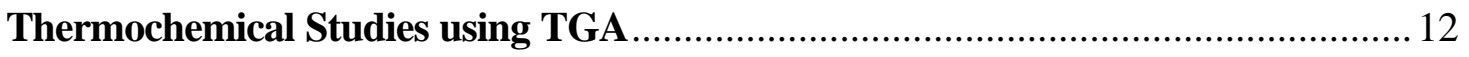

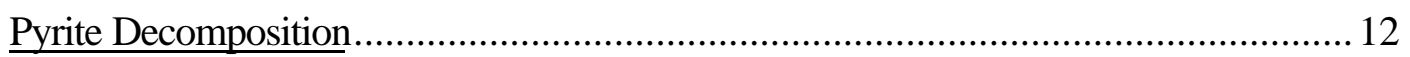

Pyrrhotite Reduction to Iron ................................................................. 15

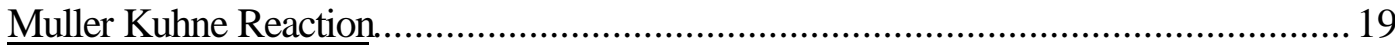

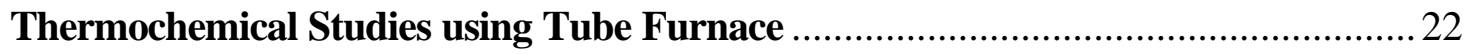




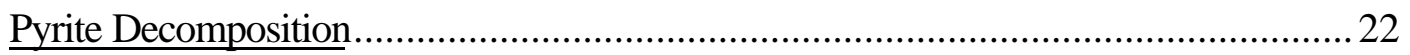

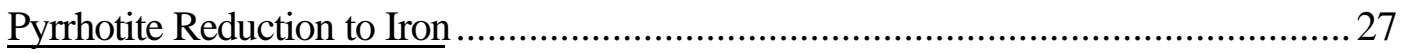

Muller Kuhne Reaction.................................................................................... 29

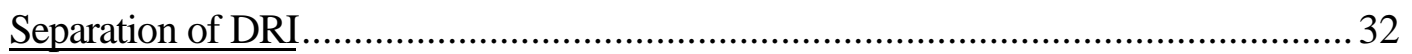

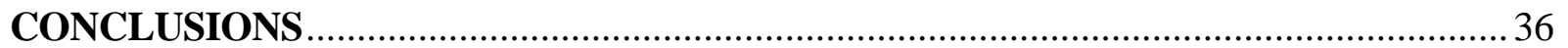

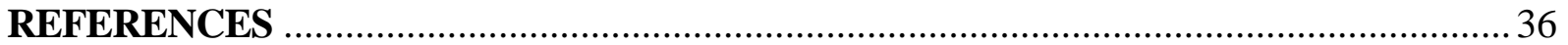




\section{ACKNOWLEDGEMENT}

We acknowledge the assistance and support of the persons listed below whose efforts made this project a success:

\section{University of Kentucky Center for Applied Energy Research}

M.A. Abdel-Khalekh

Z. Chen

J. Wiseman

University of Kentucky Department of Chemical Engineering

E. Grulke

\section{University of Minnesota Department of Civil Engineering}

M.T. Hepworth

\section{LG\&E Energy Services}

Oz Haeberlin

We also acknowledge, with thanks, guidance provided by Robert A. Patton, Project Manager, National Energy Technology Laboratory, Pittsburgh, PA. Financial assistance provided by the USDOE UCIG program is also greatly appreciated.

D.P. Tao (PI)

B.K. Parekh (Co-PI)

J. Sottile (Co-PI) 


\section{LIST OF FIGURES}

Figure 1. Schematic illustration of proposed pyrite/FGD gypsum waste disposal process..................... 7

Figure 2. Pyrite concentration flowsheet using Falcon Concentrator ............................................. 9

Figure 3. Grade-recovery curve for pyrite concentration using Falcon Concentrator............................10

Figure 4. Effect of bowl speed on the separation performance ................................................ 10

Figure 5. Effect of the specific gravity of the medium on the recovery and assay of the pyrite................11

Figure 6. Effect of xanthate and Areo 633 dosages on the pyrite grade using flotation...........................12

Figure 7. Effect of temperature on decomposition rate of pure pyrite using TGA ...............................13

Figure 8. Effect of temperature on decomposition rate of $90 \%$ pyrite using TGA..............................13

Figure 9. Effect of temperature on decomposition rate of $70 \%$ pyrite using TGA.............................14

Figure 10. Activation energy for reaction 1 using pyrite sample with different purity ...........................14

Figure 11. Effect of temperature on the kinetics of Reaction 2 using pyrrhotite derived from pure pyrite

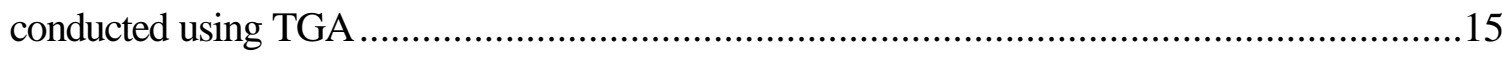

Figure 12. Activation Energy of pyrrhotite reduction calculated from Figure 11 .................................16

Figure 13. XRD $(\mathrm{Cu} \mathrm{K} \alpha 1$ radiation, $\lambda=0.15406 \mathrm{~nm})$ pattern of reaction products............................16

Figure 14. Effect of initial composition on the reaction rate for Reaction 2 at $1000^{\circ} \mathrm{C} \ldots \ldots \ldots \ldots \ldots \ldots \ldots \ldots . . . . . . . . .17$

Figure 15. Effect of initial composition on the rate of reaction (88\% FeS) (TGA) ..............................18

Figure 16. Effect of initial composition on the reaction rate of (\%70 FeS) (TGA) ............................. 18

Figure 17. Effect of temperature on the rate of reaction of $3^{\text {rd }}$ stage. $\mathrm{CaS}: \mathrm{CaSO}_{4}=1: 3 \ldots \ldots \ldots \ldots \ldots \ldots . . . \ldots 19$

Figure 18. Activation Energy of Reaction 3 using pure reactants ................................................20

Figure 19. Effect of temperature on the rate of reaction of Reaction 3. CaS: $\mathrm{CaSO}_{4}=1: 3 \ldots \ldots \ldots \ldots \ldots . . .20$

Figure 20. Activation Energy of Reaction 3 using impure reactants ..............................................21 
Figure 21. Effect of stoichiometric ratio $\mathrm{CaS}: \mathrm{CaSO}_{4}$ on the rate of Reaction 3 using pure reactants ........21

Figure 22. Effect of stoichiometric ratio $\mathrm{CaS}: \mathrm{CaSO}_{4}$ on the rate of Reaction 3 using impure reactants.....22

Figure 23. Effect of temperature on the kinetics of Reaction 1 using pure pyrite in tube furnace (with 0.5

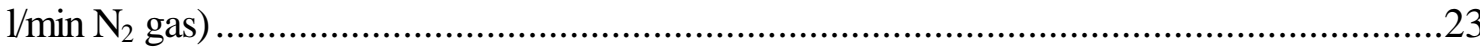

Figure 24. Activation Energy of Reaction 1 conducted using tube furnace .....................................23

Figure 25. Effect of Temperature on reaction rate of Reaction 1 using $70 \%$ pyrite in tube furnace. (0.5

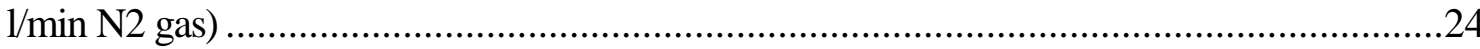

Figure 26. Activation Energy of Reaction 1 conducted using tube furnace ......................................24

Figure 27. Effect of particle size on the rate of pyrite decomposition in tube furnace. $\left(800^{\circ} \mathrm{C}, 0.5 \mathrm{l} / \mathrm{min}\right.$

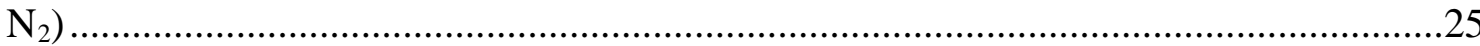

Figure 28. Effect of particle size on the rate of $90 \%$ pyrite decomposition in tube furnace. $\left(800^{\circ} \mathrm{C}, 0.5\right.$

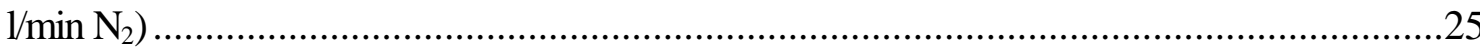

Figure 29. Effect of particle size on the rate of $70 \%$ pyrite decomposition in tube furnace. $\left(800^{\circ} \mathrm{C}, 0.5\right.$

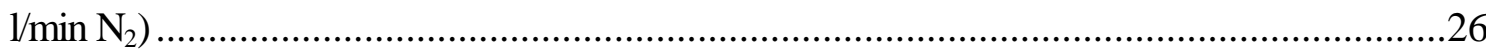

Figure 30. Effect of nitrogen gas flow rate on the rate of pyrite decomposition. $\left(30 \mathrm{~min}, 800^{\circ} \mathrm{C}\right) \ldots \ldots \ldots \ldots . .26$

Figure 31. Effect of temperature on rate of Reaction 2 in tube furnace. .........................................27

Figure 32. Activation Energy of Reaction 2 in tube furnace using pyrrhotite derived from pure pyrite.......28

Figure 33. Effect of stoichiometric ratio of reactants $\mathrm{FeS}: \mathrm{CaO}: \mathrm{C}$ on the rate of Reaction 2 in tube

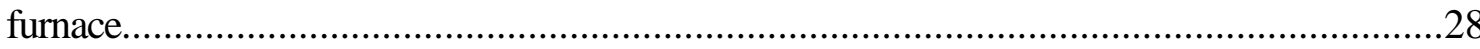

Figure 34. Effect of temperature on the reaction rate of Reaction 3 in tube furnace ............................29

Figure 35. Activation Energy of Reaction 3 in tube furnace using pure reactants ................................30

Figure 36. Effect of temperature on the reaction rate of Reaction 3 in tube furnace .............................30

Figure 37. Activation Energy of Reaction 3 in tube furnace using impure reactants..............................31

Figure 38. Effect of stoichiometric ratio $\mathrm{CaS}: \mathrm{CaSO}_{4}$ on the reaction rate of Reaction 3 in tube furnace...31 Figure 39. Effect of stoichiometric ratio $\mathrm{CaS}: \mathrm{CaSO}_{4}$ on the reaction rate of Reaction 3 in tube furnace...32 
Figure 40. Effect of magnetic intensity on sulfur content in DRI product at different reactant ratio

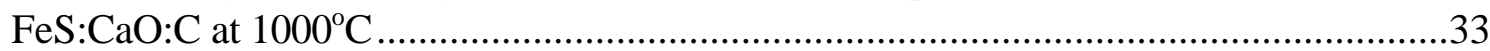

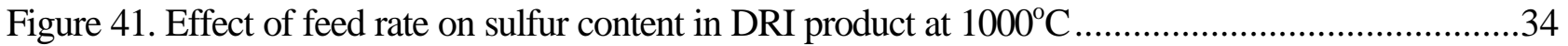

Figure 42. Effect of solid percentage on sulfur content in DRI product at $1000^{\circ} \mathrm{C}$..................................34

Figure 43. Effect of magnetic separator speed on sulfur content in DRI product at $1000^{\circ} \mathrm{C} . \ldots \ldots \ldots \ldots \ldots \ldots \ldots . . . .35$

Figure 44. Effect of temperature on sulfur content in DRI product........................................................35 


\section{EXECUTIVE SUMMARY}

This report describes the work performed under U.S. Department of Energy Program Contract No. DE-FG26-98FT40114, monitored by the National Energy Technology Laboratory (NETL), Pittsburgh, PA. The project was conducted at the Department of Mining Engineering and the Center for Applied Energy Research of University of Kentucky. The program was for 12 months which began September 30, 1998.

The main objective of this project is to develop an innovative technique for integrated disposal of pyrite and gypsum wastes. To achieve this goal, pyrite $\left(\mathrm{FeS}_{2}\right)$ was first concentrated from tailings discharged from coal-cleaning operations by means of physical separation processes such as gravity separation and flotation. This is followed by three thermochemical reactions:

$\mathrm{FeS}_{2}=\mathrm{FeS}+\mathrm{S}$.

$\mathrm{FeS}+\mathrm{C}+\mathrm{CaO}=\mathrm{Fe}^{o}+\mathrm{CaS}+\mathrm{CO}$.

$\mathrm{CaS}+3 \mathrm{CaSO}_{4}=4 \mathrm{CaO}+4 \mathrm{SO}_{2}$ (Muller - Kuhnereaction $)$.

Pyrite and gypsum were converted into marketable products such as lime, elemental sulfur and direct reduced iron (DRI). These reactions were investigated using thermogravimetric analysis (TGA) and the tube furnace.

The results of the study are summarized as follows:

1. Pyrite can be effectively concentrated using Falcon Concentrator, froth flotation, or heavy medium separation. The Falcon Concentrator produced a pyrite concentrate of $71 \%$ grade at $90 \%$ recovery. A $90 \%$ grade product was obtained at 50\% recovery with froth flotation using xanthate as pyrite collector and Areo 633 as depressant. using heavy media separation was used, $90 \%$ pure pyrite was obtained at $80 \%$ recovery.

2. TGA data has shown that pyrite decomposition to pyrrhotite (Reaction 1) can be completed in about 5 minutes at $700^{\circ} \mathrm{C}$. The reaction rate increased with increasing temperature and reactant purity and decreasing particle size. The activation energy was between 118.0 and $128.8 \mathrm{~kJ} / \mathrm{mol}$. Similar results were obtained with the tube furnace at slightly higher temperature.

3. Direct reduced iron (DRI) can be produced from pyrrhotite in the presence of $\mathrm{CaO}$ under reducing conditions (Reaction 2). The optimal temperature for this reaction is $1000^{\circ} \mathrm{C}$. The optimum stoichiometric ratio of the reactants is $\mathrm{FeS}: \mathrm{C}: \mathrm{CaO}=1: 2: 2$ which ensures the complete conversion of FeS to DRI. The activation energy calculated for the TGA was $263.0 \mathrm{~kJ} / \mathrm{mol}$. Nitrogen gas atmosphere was found to be helpful in enhancing the completion of the reaction in a tube furnace.

4. The Muller Kuhne reaction (Reaction 3) required a temperature above $1100^{\circ} \mathrm{C}$ for a reasonable reaction rate. A stoichiometric excess of lime and carbon in initial mixtures enhanced the rate of the iron production and increased the degree of reaction completion. The Muller-Kuhne process was effective in converting gypsum to lime that can be recycled to FGD processes. The excess of $\mathrm{CaSO}_{4}$ significantly enhanced the kinetics and degree of completion of the Muller Kuhne reaction. Higher reaction rate was achieved with smaller reactant particle size.

5. Magnetic separation can be used to separate DRI and calcium sulfide, producing a magnetic product that recovers $97.5 \%$ iron and only $13.3 \%$ calcium and $11.3 \%$ sulfur. 


\section{INTRODUCTION}

The 1990 Clean Air Act Amendments (CAAA) require coal-burning utilities reduce sulfur dioxide $\left(\mathrm{SO}_{2}\right)$ emissions to $1.2 \mathrm{lb}$ per million Btu by the year 2000. Pre-combustion coal cleaning and postcombustion flue gas desulfurization (FGD) processes using lime or limestone are the primary means used to achieve the compliance. Coal cleaning produces cleaner and higher-calorie coal products for utilities by reducing pyritic sulfur and other ash forming minerals. FGD processes prevent sulfur dioxide formed during coal combustion from releasing to air and forming acid rain.

Coal cleaning and FGD processes produce millions of tons of gypsum and pyrite wastes annually in the coal-related energy industry. The American Coal Ash Association [1] reported that about 20 million tons of FGD by-product gypsum $\left(\mathrm{CaSO}_{4}\right)$ was produced in 1991. U.S. Environmental Protection Agency [2] predicts that about 50 million tons of FGD by-products will be produced by the year 2000 from burning high sulfur coal for generation of electricity using Clean Coal Technology (CCT). FGD processes also consume millions of tons of limestone and lime. General Accounting Office [3] estimated that $40 \%$ lime or $70 \%$ limestone produced in the U.S. is used for FGD processes. Calcination of limestone releases tremendous amounts of carbon dioxide into atmosphere as a greenhouse gas, which is believed to cause global warming. The binding treaty signed by the U.S. government on the 1997 International Conference on Global Climate Change in Kyoto, Japan requires a drastic reduction in carbon dioxide emissions in the U.S.

Pyrite $\left(\mathrm{FeS}_{2}\right)$ is ubiquitous in the earth's crust and exists in significant quantities in many coal and mineral (zinc, lead, copper, uranium, gold, silver, etc.) deposits. The Commonwealth of Kentucky produces about 40 million tons of high sulfur coal that contains about $7 \%$ pyrite. About half of pyrite in the coal or 2.8 million tons is discarded into tailing ponds. Other five major high sulfur coal producing states, i.e., Illinois, Indiana, Ohio, Pennsylvania, and Virginia, generate similar amounts of pyrite wastes [4]. It is estimated that about 10 million tons of pyrite is discarded every year from high sulfur coal production in these six states. Mining and processing of other minerals also produce huge amounts of pyrite wastes.

Gypsum and pyrite wastes are currently landfilled although efforts have been made to use FGD byproducts in road construction, acid soil neutralization, material production, etc. [5]. Pyrite contains heavy metals such as arsenic, cobalt, copper, lead, nickel, and zinc [6]. When pyrite waste is exposed to air and ground water or rain in impoundments, it readily oxidizes, forming large amounts of acid and releasing soluble toxic substances that pollute land and water sources. The coal mining industry alone spends about half billion dollars a year to neutralize acids produced from pyrite oxidation [7]. It is estimated that pyrite-containing wastes pollute over 12,000 miles of river and streams and 180,000 acres of lakes and reservoirs in the U.S. [8]. Similarly, impoundment of gypsum wastes imposes the risk of continuous leaching of environmentally undesirable constituents into the groundwater and streams. Landfilling of pyrite and gypsum wastes also occupies thousands of acres of land. The average size of a U.S. landfill encompasses 173 acres and has a potential capacity of six to seven million tons [9]. This suggests that landfilling of 50 million tons of FGD by-products alone will consume more than 1236 acres of land per year. An environmentally sustainable approach to disposing of pyrite and gypsum wastes is critical for continued existence and growth of coal-based energy industries. 
In this study, an integrated waste disposal process was developed to eliminate millions of tons of gypsum and pyrite wastes by thermochemically converting them to marketable products such as lime, direct reduced iron (DRI), elemental sulfur, and concentrated sulfur dioxide.

\section{OBJECTIVES}

The objective of this research program is to develop a novel integrated process to eliminate millions of tons of gypsum and pyrite wastes generated annually by the U.S. energy industries and reduce the emission of millions of tons of greenhouse gas carbon dioxide. This was accomplished by converting gypsum and pyrite wastes to marketable products such as lime, direct reduced iron (DRI), and sulfur products and obviating the need to calcine millions of tons of limestone for use in utility scrubbers. Specific objectives included:

1. Develop a novel, integrated process for utilizing two major wastes generated by mining and energy industries to produce lime for recycling and other marketable products.

2. Study individual chemical reactions involved in pyrite decomposition, DRI production, and Muller-

Kuhne process for lime regeneration to determine optimum process variables such as temperature, time, and reactant composition.

3. Investigate techniques for effective concentration of pyrite from tailing waste and methods for effective separation of DRI from calcium sulfide.

\section{BACKGROUND}

High-sulfur coals are often pre-cleaned using physical separation techniques such as dense medium separation and flotation prior to combustion to remove pyrite and other ash forming minerals, producing millions of tons of tailings that contain a significant quantity of pyrite. When this waste is dumped into a tailing pond, pyrite oxidation takes place via the following electrochemical reactions in the presence of air and water [10-11]:

$n \mathrm{FeS}_{2}+3(n-2) \mathrm{OH}^{-}=2 \mathrm{FeS}_{n}+(n-2) \mathrm{Fe}(\mathrm{OH})_{3}+3(n-2) e^{-}$.

$\mathrm{FeS}_{2}+8 \mathrm{H}_{2} \mathrm{O}=\mathrm{Fe}^{3+}+2 \mathrm{SO}_{4}^{2-}+16 \mathrm{H}^{+}+15 e^{-}$.

The electrons released from anodic reactions (4) and (5) are often consumed by cathodic oxygen reduction reaction (6) [12]:

$\mathrm{O}_{2}+2 \mathrm{H}_{2} \mathrm{O}+4 e^{-}=4 \mathrm{OH}^{-}$.

Reaction (4) represents the initial oxidation of pyrite and reaction (5) the aggressive oxidation in the later stage. Reaction (5) produces large amounts of acid which in turn leaches out hazardous metals associated with pyrite such as arsenic, cobalt, copper, lead, mercury, nickel, and zinc, polluting land and water resources [6]. This creates a liability for the coal and mineral mining companies. Apparently, disposal of pyrite wastes by impoundment is not an environmentally sustainable approach.

Flue gas desulfurization (FGD) of coal-burning power plants using lime or limestone can be represented by the reaction [13]: 


$$
\mathrm{CaO}+\mathrm{SO}_{2}+\frac{1}{2} \mathrm{O}_{2}=\mathrm{CaSO}_{4} \text {, or } \mathrm{CaCO}_{3}+\mathrm{SO}_{2}+\frac{1}{2} \mathrm{O}_{2}=\mathrm{CaSO}_{4}+\mathrm{CO}_{2} \text {. }
$$

Although efforts have been made to use FGD by-product gypsum $\left(\mathrm{CaSO}_{4}\right)$ in road construction, acid soil neutralization, material production, etc. [5], FGD by-products are often impounded on land. Millions of tons of FGD by-products produced from coal-burning power plants occupy thousands of acres of land and are a major source of environmental contamination [9].

The investigated process utilized both pyrite and gypsum wastes to regenerate lime for FGD processes and simultaneously produce some salable products, including direct reduced iron (DRI) and sulfur products (concentrated $\mathrm{SO}_{2}$ and elemental sulfur). If fifty (50) million tons of gypsum and thirteen (13) million tons of pyrite wastes produced annually by the year 2000 [2] are treated using this approach, land and water pollution problems caused by these wastes will be eliminated. Moreover, twenty one (21) million tons of lime, seven (7) million tons of DRI, thirty one (31) million tons of concentrated sulfur dioxide, and four (4) million tons of elemental sulfur will be produced. The process obviates the need to calcine thirty seven (37) million tons of limestone needed for FGD process by the year 2000 [2]. As a result, a net reduction of eleven (11) million tons of greenhouse gas (carbon dioxide) will be achieved. This integrated approach of waste utilization will help mining companies and utilities reduce waste disposal costs by billions of dollars and operate in an environmentally sustainable system.

The process primarily consisted of four steps:

1. Pyrite $\left(\mathrm{FeS}_{2}\right)$ is concentrated from tailings discharged from coal-cleaning operations. This can be achieved by physical separation processes such as gravity separation and flotation [14]. These processes are based on the difference in specific gravity of pyrite and other tailing components, surface hydrophobicity, surface charge, and interactions with the chemical reagents added [15-16]. The most effective gravity concentrator for pyrite separation from coal may be the Falcon Concentrator [17-18], which has been extensively tested for coal cleaning.

2. Pyrite is thermally decomposed to pyrrhotite (FeS) and elemental sulfur:

$$
\mathrm{FeS}_{2}=\mathrm{FeS}+\mathrm{S} \text {. }
$$

This reaction requires a non-oxidizing atmosphere and a temperature of $650-700^{\circ} \mathrm{C}$ for favorable kinetics [19]. The labile sulfur vapor from the decomposition of pyrite will be removed by condensation. The composition of pyrrhotite produced depends on the reaction temperature, retention time, and particle size of pyrite.

The process of thermal decomposition of pyrite has been studied by several investigators [19-21]. It is known that pyrite is readily decomposed above $650^{\circ} \mathrm{C}$ under non-oxidizing conditions. Mehta and O'Kane [20] reported a S/Fe ratio in the pyrrhotite equal to 1.15. Their results show that about $42 \%$ of sulfur can be removed by thermal decomposition, which is confirmed in our preliminary studies.

3. Pyrrhotite is reacted with lime in a reducing environment at $900-1000^{\circ} \mathrm{C}$ to form calcium sulfide and direct reduced iron (DRI) [22]:

$$
\mathrm{FeS}+\mathrm{C}+\mathrm{CaO}=\mathrm{Fe}^{o}+\mathrm{CaS}+\mathrm{CO} .
$$


Steps 2 and 3 can be accomplished as a two-stage fluidized-bed process with reaction (8) as the first stage and reaction (9) as the second stage. The hot off-gas, rich in $\mathrm{CO}$ from the second stage would provide the enthalpy for the first stage of reactions.

Production of iron and $\mathrm{CaS}$ from pyrite by reduction with lime was piloted by Phelps Dodge to precipitate copper from dump-leach solutions containing copper sulfate [23]. It was found that under neutral or slightly reducing conditions and at about $850^{\circ} \mathrm{C}$, pyrite with 2 mole ratios of lime produced a $\mathrm{CaS}$ precipitant and inert iron oxide according to the reaction:

$$
6 \mathrm{FeS}_{2}+12 \mathrm{CaO}=11 \mathrm{CaS}+2 \mathrm{Fe}_{3} \mathrm{O}_{4}+\mathrm{CaSO}_{4} .
$$

Under highly reducing conditions using charcoal or coal and at a temperature of about $950^{\circ}$ $\mathrm{C}$, the prefered precipitant comprising metallic iron and $\mathrm{CaS}$ was produced as shown in the reaction:

$$
\mathrm{FeS}_{2}+2 \mathrm{CaO}+2 \mathrm{C}=2 \mathrm{CaS}+\mathrm{Fe}^{o}+2 \mathrm{CO} .
$$

Use of lime for enhancing the direct reduction of metal sulfides to form the metal and calcium sulfide has been extensively studied using hydrogen as the reductant [24-28]. The generalized overall reaction is written as:

$$
\mathrm{MS}+\mathrm{H}_{2}+\mathrm{CaO}=\mathrm{M}+\mathrm{CaS}+\mathrm{H}_{2} \mathrm{O} .
$$

where $\mathrm{M}$ represents metal. Results showed that mineral sulfides of copper, nickel, cobalt, and iron respond with comparable kinetics in the temperature range of 700 to $900^{\circ} \mathrm{C}$.

The mechanical separation of the iron product produced in reaction (9) is necessary for the process to proceed. Magnetic separation was applied successfully to separate sponge iron and iron-nickel alloy from calcium sulfide following reductions of a pentlandite concentrate with hydrogen in the presence of lime [26,29,30]. However, no work has been reported on the separation of iron from calcium sulfide produced by pyrrhotite reduction by coal in the presence of calcium oxide.

4. Calcium sulfide is employed as a reductant to react with gypsum wastes to produce lime and sulfur dioxide at temperatures of about $900^{\circ} \mathrm{C}$ :

$$
\mathrm{CaS}+3 \mathrm{CaSO}_{4}=4 \mathrm{CaO}+4 \mathrm{SO}_{2} .(\text { Muller }- \text { Kuhnereaction })
$$

The Muller Kuhne reaction of calcium sulfate with sulfide is primarily involved in the industrial production of cement clinker by the addition of fly ash and sand to react with the $\mathrm{CaO}$ [31]. The individual reactions in this process are:

$\mathrm{CaSO}_{4}+2 \mathrm{C}=\mathrm{CaS}+2 \mathrm{CO}_{2}$.

$\mathrm{CaS}+3 \mathrm{CaSO}_{4}=4 \mathrm{CaO}+4 \mathrm{SO}_{2}$.

$8 \mathrm{CaO}+\mathrm{Al}_{2} \mathrm{Si}_{2} \mathrm{O}_{7}=\left(2 \mathrm{Ca}_{3} \mathrm{SiO}_{5}+\mathrm{Ca}_{2} \mathrm{Al}_{2} \mathrm{O}_{5}\right)$.

where $\left(2 \mathrm{Ca}_{3} \mathrm{SiO}_{5}+\mathrm{Ca}_{2} \mathrm{Al}_{2} \mathrm{O}_{5}\right)$ represents simplified clinker composition.

Production of lime and elemental sulfur as end-products from gypsum was commercialized 
by Elcor using a variation of the Muller-Kuhne chemistry conducted in a vertical kiln using natural gas as reductant [32]. The reactions can be summarized as follows:

$$
\begin{aligned}
& 2 \mathrm{CaSO}_{4}+\mathrm{H}_{2}+\mathrm{CO}=2 \mathrm{CaO}+2 \mathrm{SO}_{2}+\mathrm{H}_{2} \mathrm{O}+\mathrm{CO}_{2} . \\
& \mathrm{CaSO}_{4}+2 \mathrm{H}_{2}+2 \mathrm{CO}=\mathrm{CaS}+2 \mathrm{H}_{2} \mathrm{O}+2 \mathrm{CO}_{2} . \\
& \mathrm{CaS}+\mathrm{H}_{2} \mathrm{O}+\mathrm{CO}_{2}=\mathrm{H}_{2} \mathrm{~S}+\mathrm{CaCO}_{3} . \\
& 2 \mathrm{H}_{2} \mathrm{~S}+\mathrm{SO}_{2}=\mathrm{S}_{3}+2 \mathrm{H}_{2} \mathrm{O} .
\end{aligned}
$$

Reactions (17) and (18) took place in the kiln and reaction (19) in aqueous solution.

Wheelock and Boylan [33] used another variation of the Muller-Kuhne chemistry in fluidized bed reactors using both anhydrite and natural gypsum. The net reaction can be represented by reaction (17). A conversion of $96 \%$ of the calcium sulfate to lime and sulfur dioxide was achieved at a reaction temperature of about $1200^{\circ} \mathrm{C}$.

The overall thermochemical reaction of the proposed process obtained by combining reactions (8), (9), and (13) can be represented by:

$$
\begin{aligned}
& \mathrm{FeS}_{2}+3 \mathrm{CaSO}_{4}+\mathrm{C}+\frac{1}{2} \mathrm{O}_{2} \\
& \quad=\mathrm{Fe}^{o}+3 \mathrm{CaO}+4 \mathrm{SO}_{2}+\mathrm{S}+\mathrm{CO}_{2} .
\end{aligned}
$$

Reaction (22) indicates that one mole of $\mathrm{FeS}_{2}(120 \mathrm{~g})$ will react with three moles of $\mathrm{CaSO}_{4}$ (408 g) to convert pyrite and gypsum wastes to one mole of Fe $(56 \mathrm{~g})$, three moles of $\mathrm{CaO}$ (168 g), four moles of $\mathrm{SO}_{2}(256 \mathrm{~g})$, and one mole of elemental sulfur (32g). The most significant product from reaction (22) is $\mathrm{CaO}$ that will be fed back to the FGD process. The overall process discussed above is schematically shown in Figure 1.

A very important feature of reaction (22) is that it produces only one mole of greenhouse gas $\mathrm{CO}_{2}$ for every three moles of $\mathrm{CaO}$. In contrast production of $\mathrm{CaO}$ by calcination of limestone will generate one mole of $\mathrm{CO}_{2}$ for every mole of $\mathrm{CaO}$ as shown in reaction (23):

$\mathrm{CaCO}_{3}=\mathrm{CaO}+\mathrm{CO}_{2}$.

This shows that regeneration of $\mathrm{CaO}$ from gypsum and pyrite wastes can reduce two thirds of carbon dioxide emission compared to the conventional limestone calcination process. The environmental benefits of the new process are tremendous. It not only eliminates millions of tons of solid wastes, but also reduces millions of tons of greenhouse gas. The production of twentyone million tons of lime needed for the FGD process by the year 2000 [2] from fifty million tons of gypsum waste using the proposed process, rather than calcining thirty seven million tons of limestone, would cut greenhouse gas emission by eleven million tons.

The individual reaction processes described above have extensive experimental and some commercial background; however, the integrated concept has no precedent. A systematic investigation of all reactions involved in the process was conducted to establish the technical feasibility of the proposed process. 


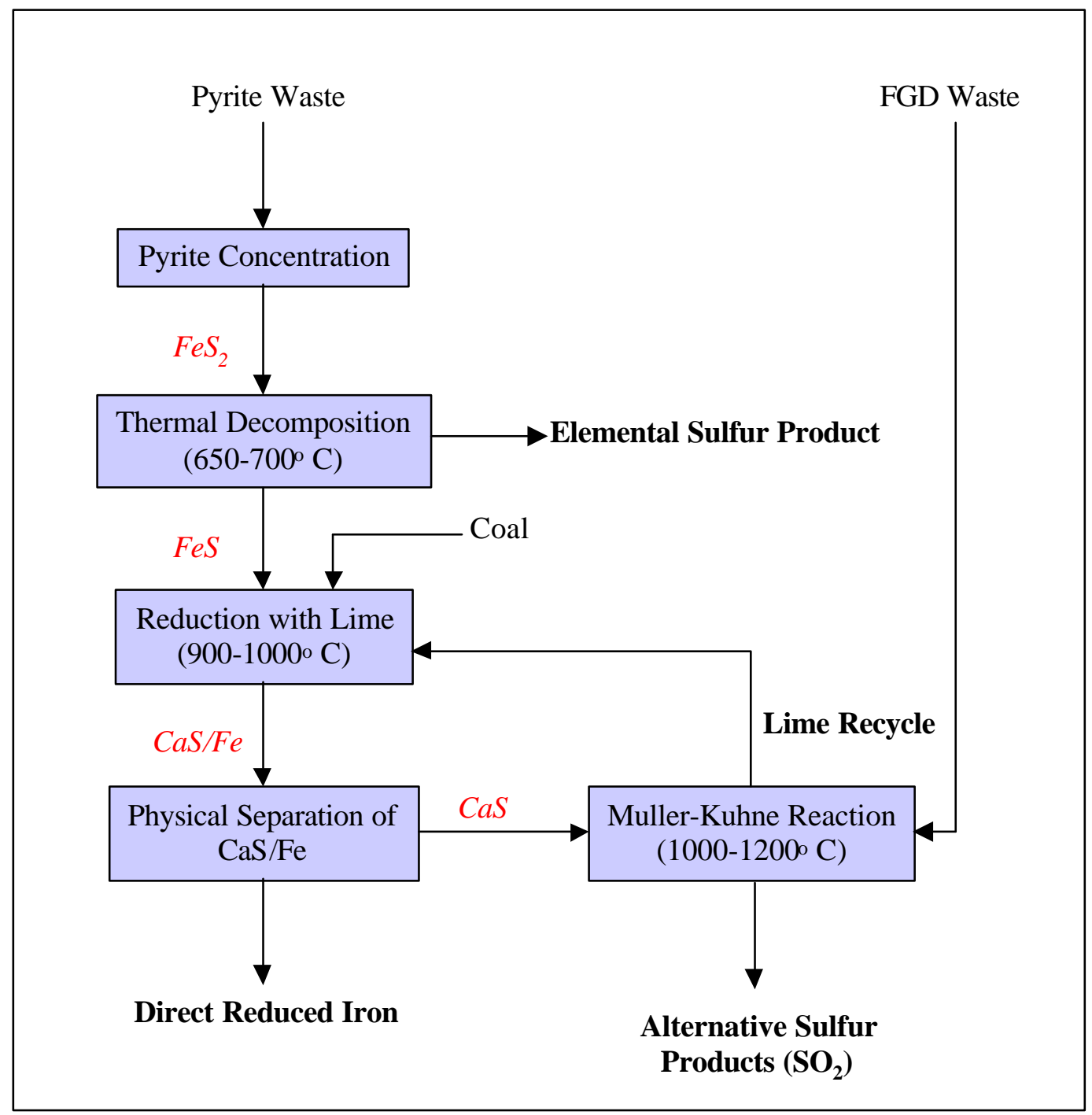

Figure 1. Schematic illustration of proposed pyrite/FGD gypsum waste disposal process. 


\section{EXPERIMENTAL}

\section{$\underline{\text { Material }}$}

Chemical grade $\mathrm{CaSO}_{4}$, carbon black, $\mathrm{CaO}$ and $\mathrm{CaS}$ were purchased from Fisher Scientific. Specimen-grade pyrite and pyrrhotite from Zacatecas, Mexico, were obtained from Ward's Natural Science Est., Inc. The mineral pyrite and pyrrhotite contain $>99.5 \% \mathrm{FeS}_{2}$ and $\mathrm{FeS}$, respectively.

Samples of pyrite waste and FGD gypsum waste were obtained from the pyrite rejection machine and flue gas scrubber, respectively, of an LG\&E midwestern power plant. The gypsum sample was in the form of slurry which contained $15.29 \%$ solids, $223.6 \mathrm{mg} / \mathrm{g} \mathrm{Ca}^{2+}, 1.22 \mathrm{mg} / \mathrm{g} \mathrm{Mg}^{2+}, 356.38 \mathrm{mg} / \mathrm{g}$ $\mathrm{SO}_{4}{ }^{2-}$. The slurry $\mathrm{pH}$ was 5.83 . The water was decanted after solids settled and the sample was dried at room temperature. The pyrite sample that contained about $54 \%$ pyrite was crushed and screened to different size fractions prior to its use.

$\underline{\text { Instrumentation and experimental procedures }}$

TGA tests: A Dupont 2000 Thermogravimetric Analyzer was used for the theoretical study of reaction kinetics. For each TGA test, about $40 \mathrm{mg}$ of sample was used. The reaction completion was reported automatically by the percent weight remained in the sample pan monitored by a computer. Nitrogen gas was purged during the entire reaction duration to prevent oxidation of the reactants and products. The disadvantage of this procedure was that the temperature can only be adjusted after the sample was introduced to the reaction chamber. Hence, the actual starting temperature of the sample chamber was the room temperature rather than the desired decomposition temperature. As a result, some degree of reaction had already occurred by the time the reaction chamber reached the desired decomposition temperature even though the temperature increase was pre-set at the highest rate. To truly reflect the weight loss occurred at the desired temperature, the temperature of the reaction chamber was also monitored as a function of time. The weight loss before reaching the desired reaction temperature was subtracted from the initial weight of the sample, and the percentage weight loss was recalculated using the weight at which the temperature reached the desired value as the initial total weight.

Tube Furnace: A Lindburg Tube Furnace from General Signal Inc. was used for the larger scale reaction kinetics study. For each test, about 20 grams of reactant was placed in a ceramic boat which was $16 \mathrm{~mm}$ in width, $80 \mathrm{~mm}$ in length and $12 \mathrm{~mm}$ in height. The furnace was pre-heated to the desired temperature before the boat was introduced to the reaction zone. After the pre-determined reaction time, the boat was pushed to the cooling zone for $>20$ minutes before taking out of the furnace to prevent the oxidation of the reactants and products that may occurr during cooling in air. Nitrogen gas was purged through the tube during the reaction duration. The product was weighed and analyzed after each test. 


\section{RESULTS AND DISCUSSION}

\section{Concentration of Pyrite}

Three different processes were employed to concentrate pyrite from the pyrite waste sample. They included the Falcon Concentrator, froth flotation, and heavy medium separation.

\section{$\underline{\text { The Falcon Concentrator }}$}

Figure 2 shows the processing flowsheet used for the centrifugal concentration of pyrite using an SB4 Falcon Concentrator. It consisted of the rougher, three scavengers, and the cleaner. Bowl speed of $3000 \mathrm{rpm}$ and water pressure of 3 psi were used for the rougher and scavengers. The concentrate of the rougher was subjected to further cleaning using $1200 \mathrm{rpm}$ bowl speed and 3 psi water pressure. The particle size of the pyrite sample was $-60+325$ mesh. The solid content of the original feed was $33 \%$ by weight.

Figure 3 shows the results of pyrite recovery as a function of grade obtained using the multiple stages of Falcon Concentrator concentration shown in Figure 1. A concentrate grade of $65 \%$ can be achieved at $\sim 95 \%$ recovery. Increase in the grade to $\sim 71 \%$ reduced the recovery to $\sim 40 \%$

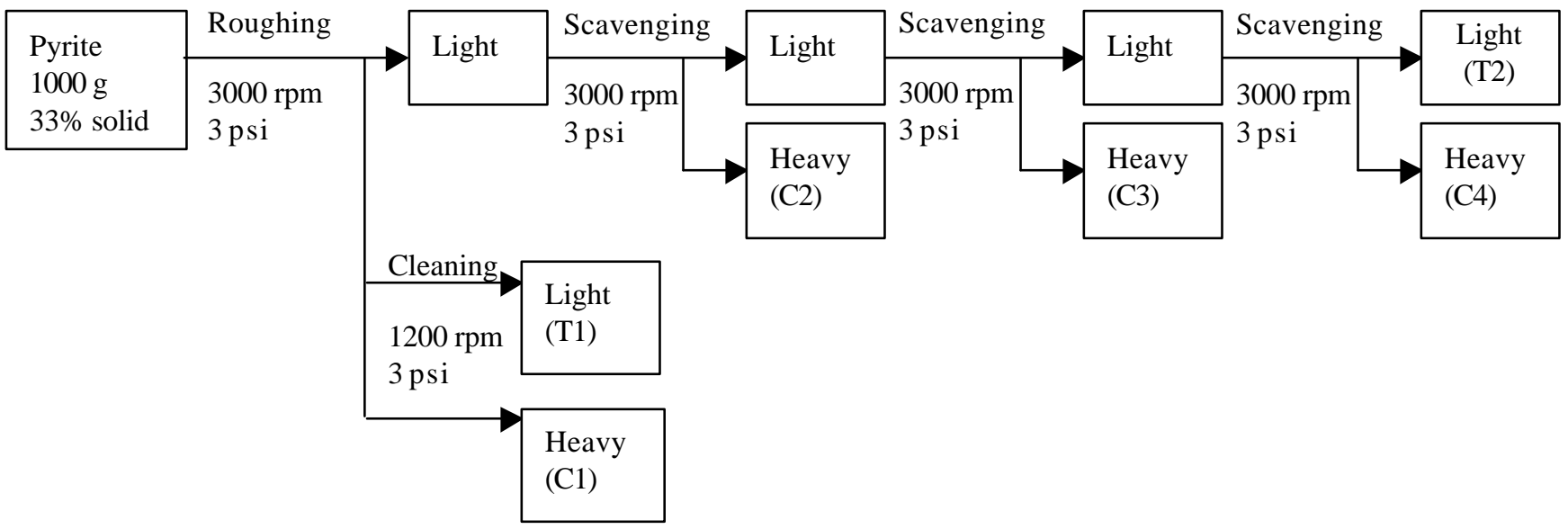

Figure 2. Pyrite concentration flowsheet using Falcon Concentrator. 


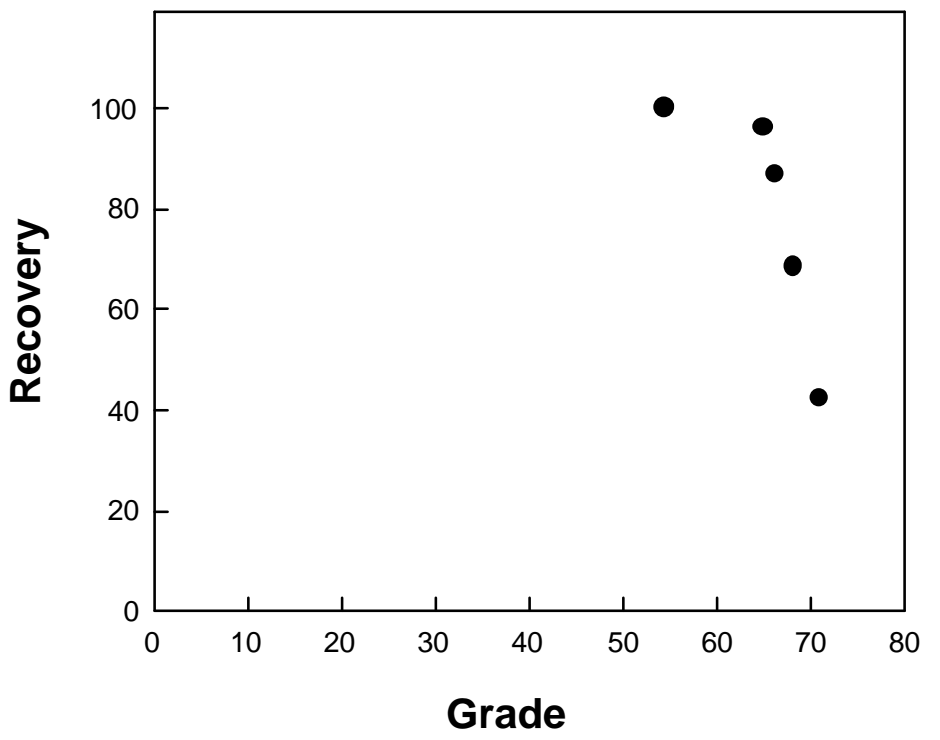

Figure 3. Grade-recovery curve for pyrite concentration using Falcon Concentrator

Figure 4 shows the effect of decreasing the bowl speed on pyrite concentration performance in a single stage, i.e., rougher. When $30 \mathrm{~Hz}$ bowl speed was used, the grade of pyrite was $71 \%$ at $91 \%$ recovery after one stage of cleaning. Further decrease in bowl speed to $20 \mathrm{~Hz}$ was detrimental to the separation performance.

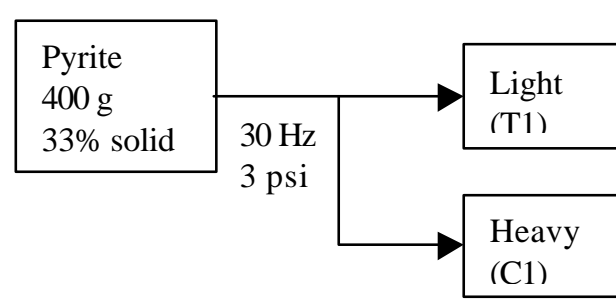

Head Sample

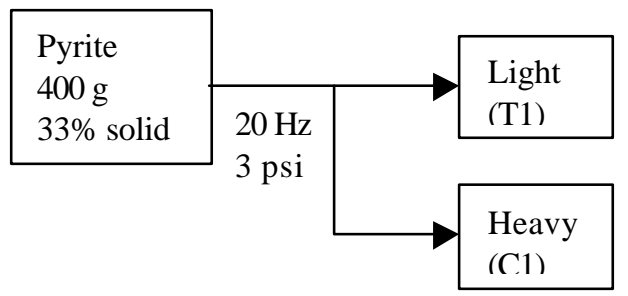

Head Sample

\section{Pyrite\% Wt\% Recovery\%}

$\begin{array}{ccc}16 & 29 & 8.54 \\ 70 & 71 & 91.46\end{array}$

54.34

Pyrite\% Wt\% Recovery\%

$\begin{array}{lll}35.4 & 34 & 22.4 \\ 63.2 & 66 & 77.6\end{array}$

53.75 
Figure 4. Effect of bowl speed on the separation performance.

\section{$\underline{\text { Dense Medium Separation }}$}

Since pyrite has a specific gravity of about 5.8, significantly greater than that of gangue components such as coal, carbonates, silicates, dense medium separation may offer an effective technique for separation of pyrite from gangue minerals. Figure 5 shows the effect of specific gravity of the dense medium on the recovery and grade of pyrite. A mixture of bromoform and acetone at different ratios was used as the dense medium. The particle size of the sample was -100 mesh. As can be seen from the figure, a product with $90 \%$ pyrite can be obtained at $\sim 80 \%$ recovery using a 4.25 specific gravity medium.

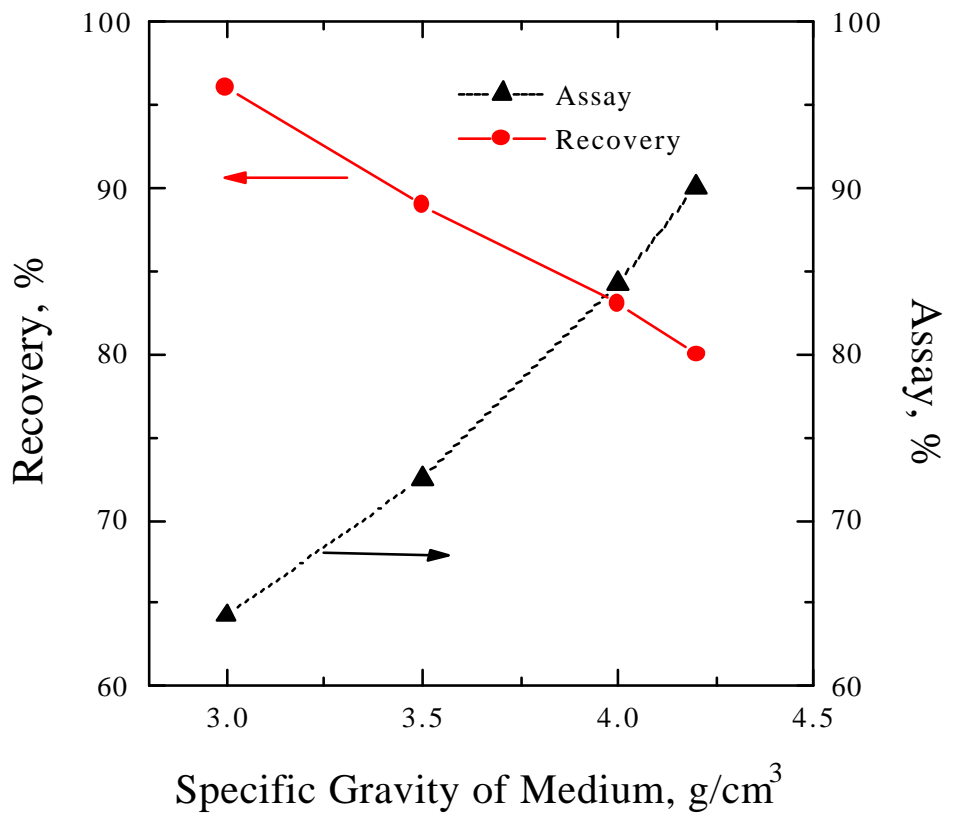

Figure 5. Effect of the specific gravity of the medium on the recovery and assay of the pyrite

\section{$\underline{\text { Froth Flotation }}$}

The concentration of pyrite may also be achieved by froth flotation using xanthate as pyrite collector and Aero 633 (starch) as depressant. Figure 6 shows the effect of xanthate and Aero 633 dosage on the pyrite grade. It can be seen that using $500 \mathrm{~g} /$ ton of xanthate and $150 \mathrm{~g} /$ ton of Aero 633, a pyrite product with $90 \%$ purity can be obtained. Higher dosages of xanthate and Aero 633 produced higher pyrite grade. 


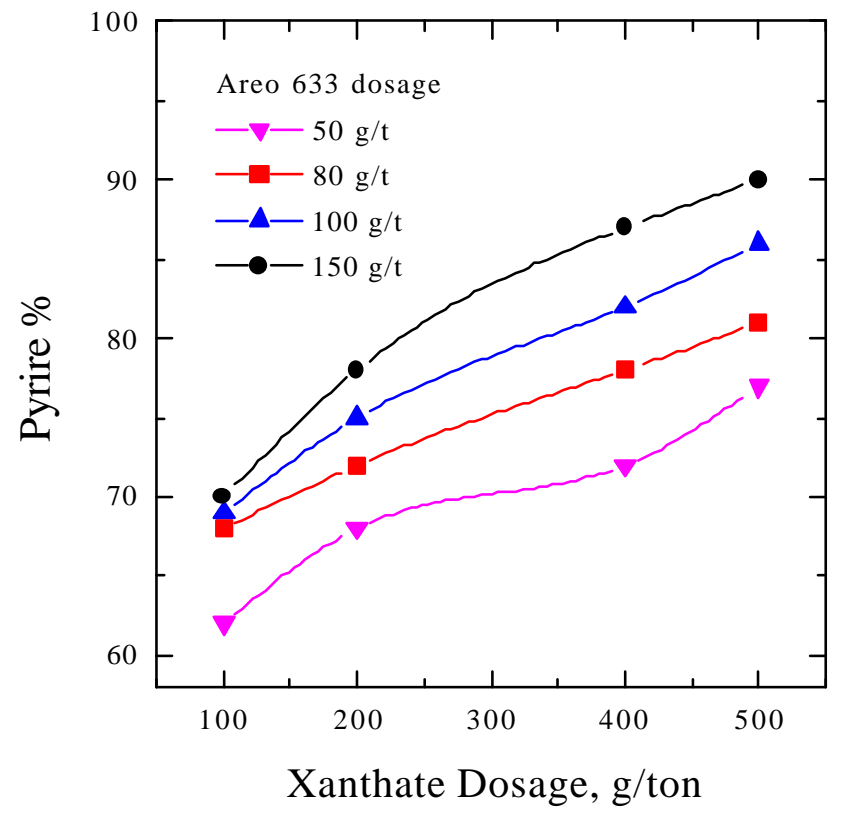

Figure 6. Effect of xanthate and Aero 633 dosages on the pyrite grade using flotation.

\section{Thermochemical Study using TGA}

The effect of temperature, sample purity and reactant ratio on the kinetics of individual thermochemical reactions was investigated using TGA. All the results reported in this section were obtained using -100 mesh pyrite samples.

$\underline{\text { Pyrite Decomposition }}\left(\mathrm{FeS}_{2}=\mathrm{FeS}+\mathrm{S}\right.$. $)$

Figure 7 shows the effect of temperature on the decomposition of pure pyrite using TGA. As can be seen, the reaction reached $95 \%$ completion in less than 2 minutes at $700^{\circ} \mathrm{C}$ while the time for $95 \%$ completion tripled to 6 minutes at $650^{\circ} \mathrm{C}$. When the temperature was further decreased to $600^{\circ} \mathrm{C}$ the reaction reached about $92 \%$ completion after 30 minutes.

When $90 \%$ or $70 \%$ grade pyrite concentrate samples were used as the reactant the reaction rate was slower compared to pure pyrite mineral, as shown in Figures 8 and 9, respectively. It can also be seen from the figures that when $90 \%$ or $70 \%$ grade pyrite was used as reactant, the maximum completion was $97 \%$ and $92 \%$, respectively. This may be because the impurities covering the pyrite surface prevented the complete decomposition of pyrite. 


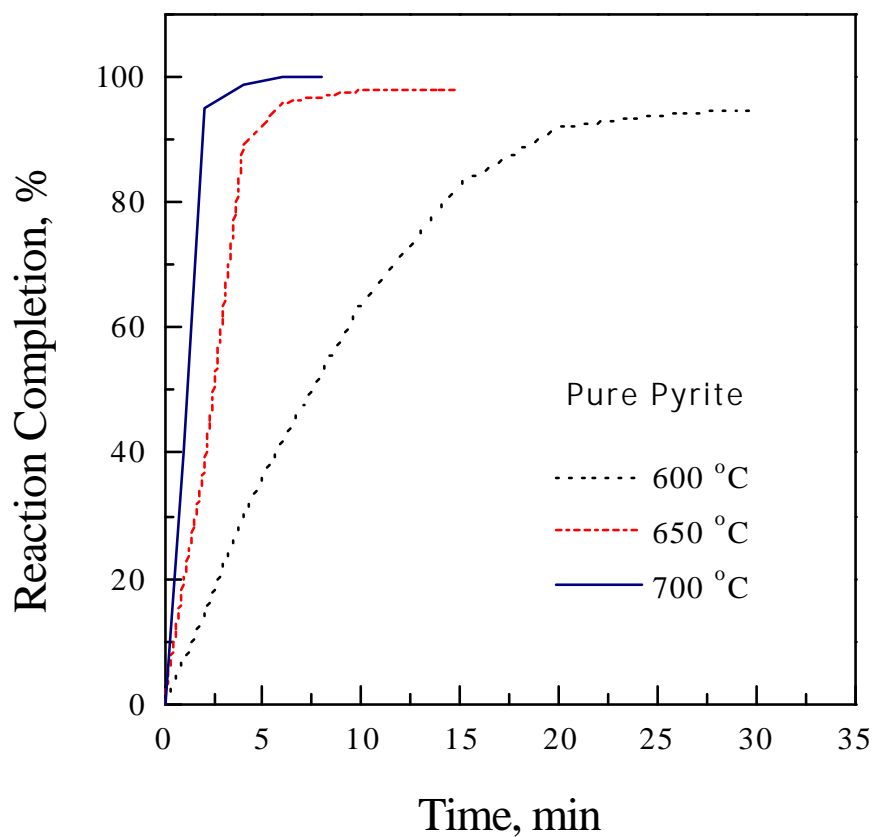

Figure 7. Effect of temperature on decomposition rate of pure pyrite using TGA.

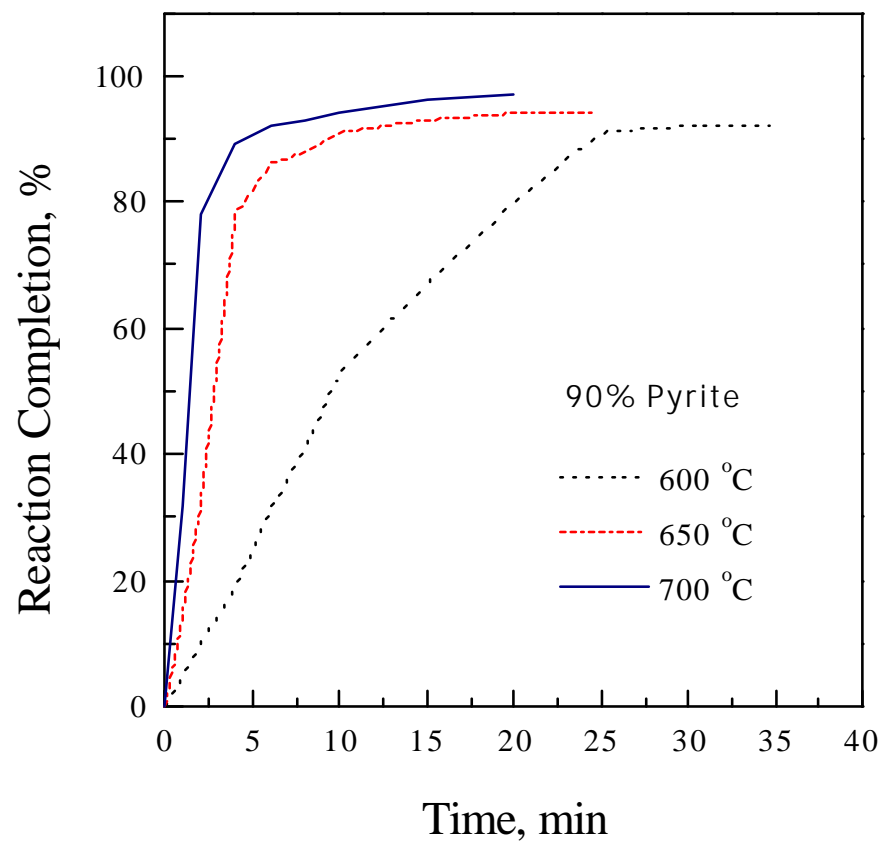

Figure 8. Effect of temperature on decomposition rate of $90 \%$ pyrite using TGA. 


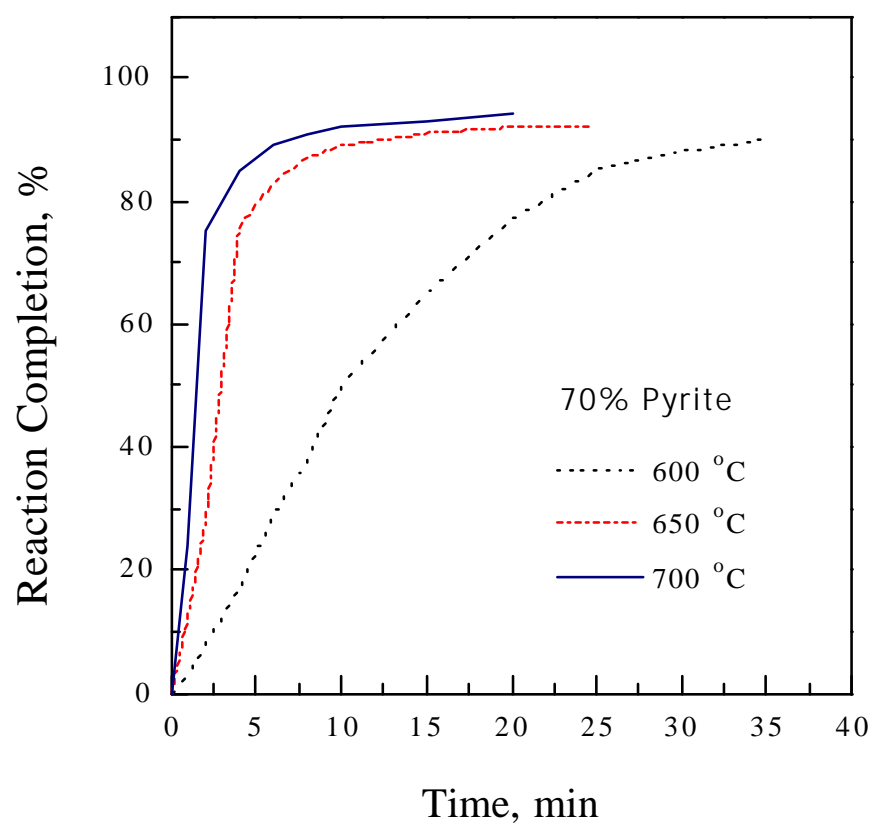

Figure 9. Effect of temperature on decomposition rate of $70 \%$ pyrite using TGA.

The effect of pyrite purity on the activation energy for pyrite decomposition is shown in Figure 10. As can be seen from this figure, when pure pyrite was used, the activation energy was determined to be $118.0 \mathrm{KJ} / \mathrm{mol}$. Decrease in pyrite purity to $90 \%$ and $70 \%$ increased the activation energy slightly to $126.1 \mathrm{~kJ} / \mathrm{mol}$ and $128.8 \mathrm{~kJ} / \mathrm{mol}$, respectively.

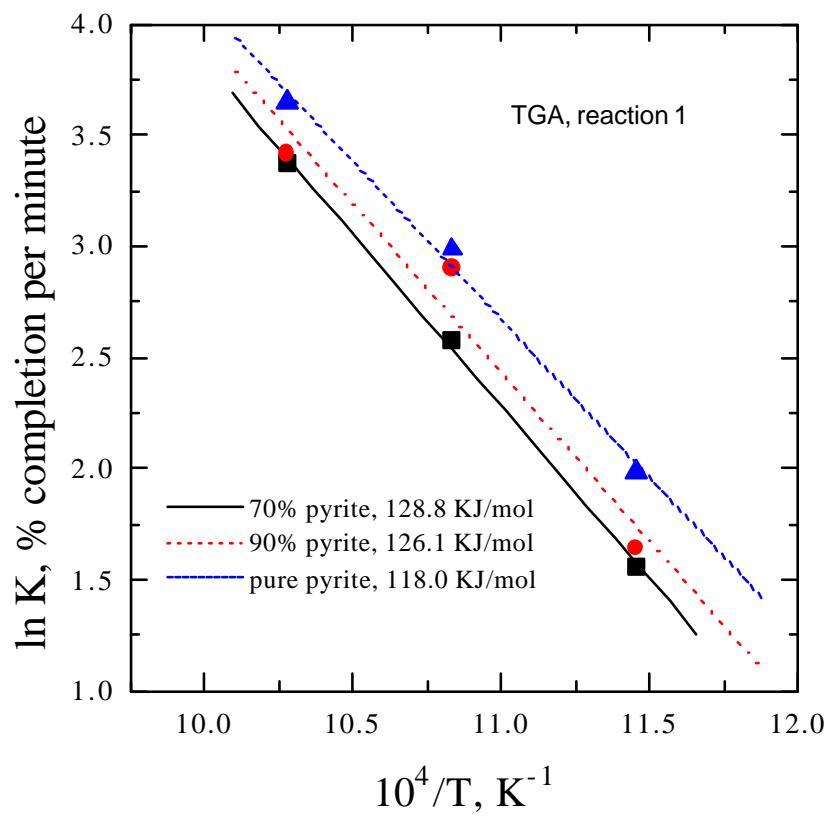

Figure 10. Activation energy for reaction 1 using pyrite sample with different purity. 
Chemical analysis performed to characterize the product formed during the reaction showed that the product had a Fe/S ratio of $\sim 1.03$, indicating that the product was most likely to be pyrrhotite (FeS).

Pyrrhotite Reduction to Iron $\left(\mathrm{FeS}+\mathrm{C}+\mathrm{CaO}=\mathrm{Fe} e^{o}+\mathrm{CaS}+\mathrm{CO}\right.$. $)$

Figure 11 shows the effect of temperature on the reaction kinetics of pyrrhotite reduction in the presence of $\mathrm{CaO}$ using pyrrhotite derived from pure pyrite. As the temperature increased, the reaction rate increased significantly. At $1100^{\circ} \mathrm{C}$, the reaction reached $95 \%$ completion in $\sim 17$ minutes. Decreasing the reaction temperature decreased the reaction rate. At $950^{\circ} \mathrm{C}$, the maximum reaction completion was $<70 \%$ even after 140 minutes. The activation energy of the reaction was determined to be $263.0 \mathrm{KJ} / \mathrm{mol}$ (Figure 12).

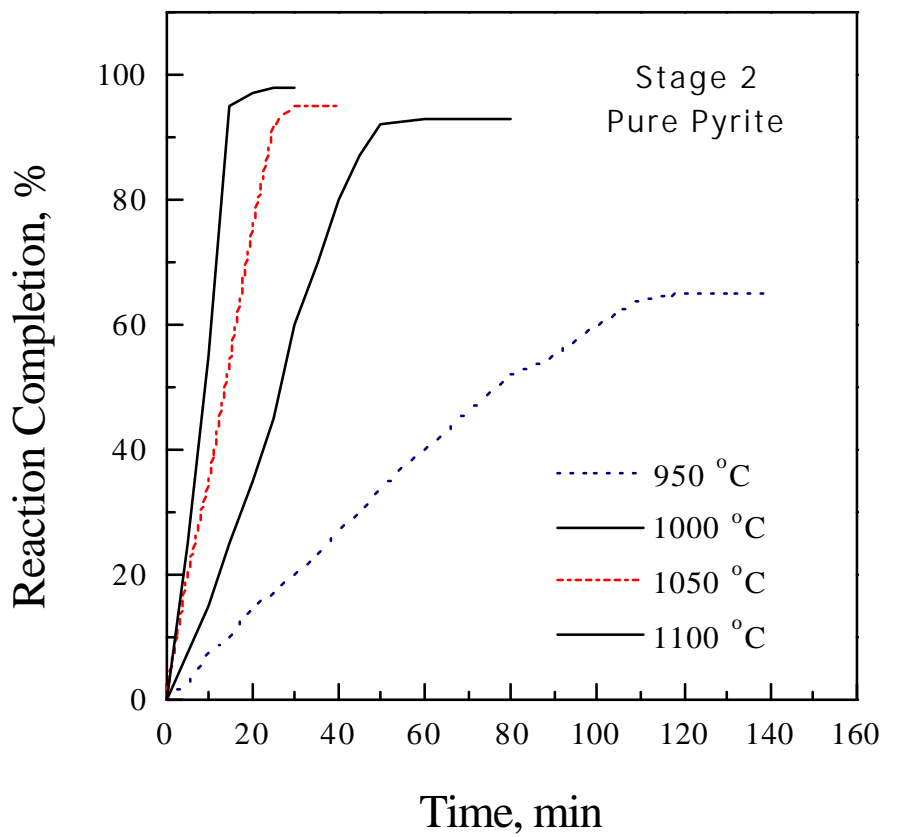

Figure 11. Effect of temperature on the kinetics of Reaction 2 using pyrrhotite derived from pure pyrite conducted using TGA. The reactant ratio is FeS:CaO:C $=1: 1.1: 1.1$ 


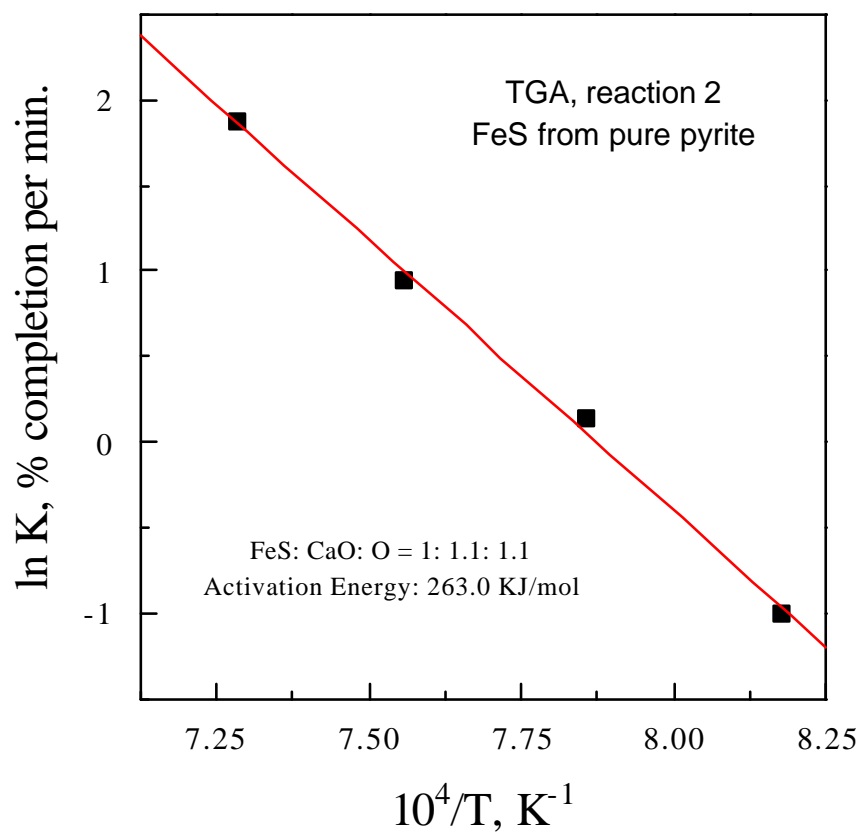

Figure 12. Activation Energy of pyrrhotite reduction calculated from Figure 11.

Figure 13 shows the X-ray diffraction (XRD) pattern of the reaction product obtained after 65 minutes of reaction at $1000^{\circ} \mathrm{C}$. The pattern consists of strong intensity peaks corresponding to calcium sulfide (C) and $\alpha$-iron (D) and weak peaks of unreacted pyrrhotite $(E)$, suggesting most reactants were converted to the products shown in reaction (2) and unreacted pyrrhotite is only in a small quantity.

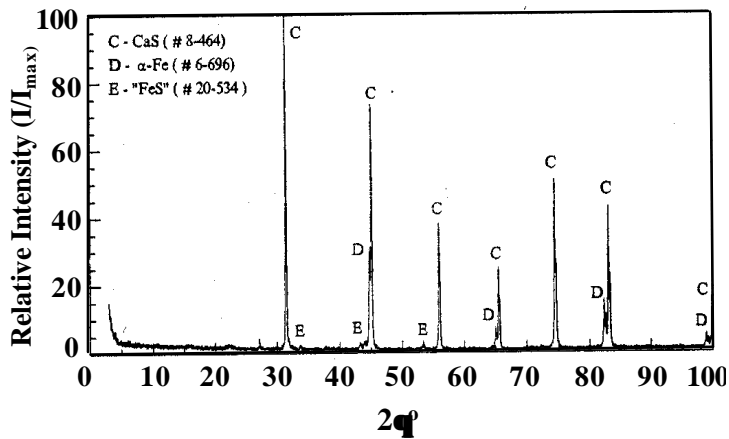

Figure 13. $\mathrm{XRD}(\mathrm{Cu} \mathrm{K} \alpha 1$ radiation, $\lambda=0.15406 \mathrm{~nm})$ pattern of reaction products.

Although the reaction rate was much faster at $1100^{\circ} \mathrm{C}$, the DRI produced at this temperature was molten, making it difficult to separate the DRI from the product mixture. Hence, $1000^{\circ} \mathrm{C}$ was used for pyrrhotite reduction in the following tests.

Figure 14 shows the effect of the stoichiometric ratio of the reactants on the rate of Reaction 2 using pyrrhotite derived from pure pyrite. The particle size of the mixture was -325 mesh. Reaction temperature was $1000^{\circ} \mathrm{C}$. When the reactant ratio for $\mathrm{FeS}: \mathrm{CaO}: \mathrm{C}$ was $1: 1: 1$, the maximum reaction 
completion of $85 \%$ was achieved. Increasing the $\mathrm{FeS}: \mathrm{CaO}: \mathrm{C}$ ratio to $1: 2: 2$ increased the maximum reaction completion to $>97 \%$ which was achieved in 35 minutes at $1000^{\circ} \mathrm{C}$. Thus, it appears that excess of $\mathrm{CaO}$ and the reductant carbon was helpful in increasing the kinetics of the reaction and achieving maximum reaction completion.

Figures 15 and 16 show the effect of the stoichiometric ratio of the reactants on the rate of Reaction 2 using pyrrhotite derived from $90 \%$ pyrite and $70 \%$ pyrite, respectively. Since chemical analysis showed that the grade of the pyrrhotite derived from $90 \%$ pyrite and $70 \%$ pyrite was $88 \%$ and $70 \%$, respectively, the stoichiometric ratio shown in Figures 15 and 16 was adjusted for the reactant impurity. Similar to Figure 14, the optimal reactant ratio was FeS:CaO:C = 1:2:2 in both cases, which gave 95\% completion in 35 minutes.

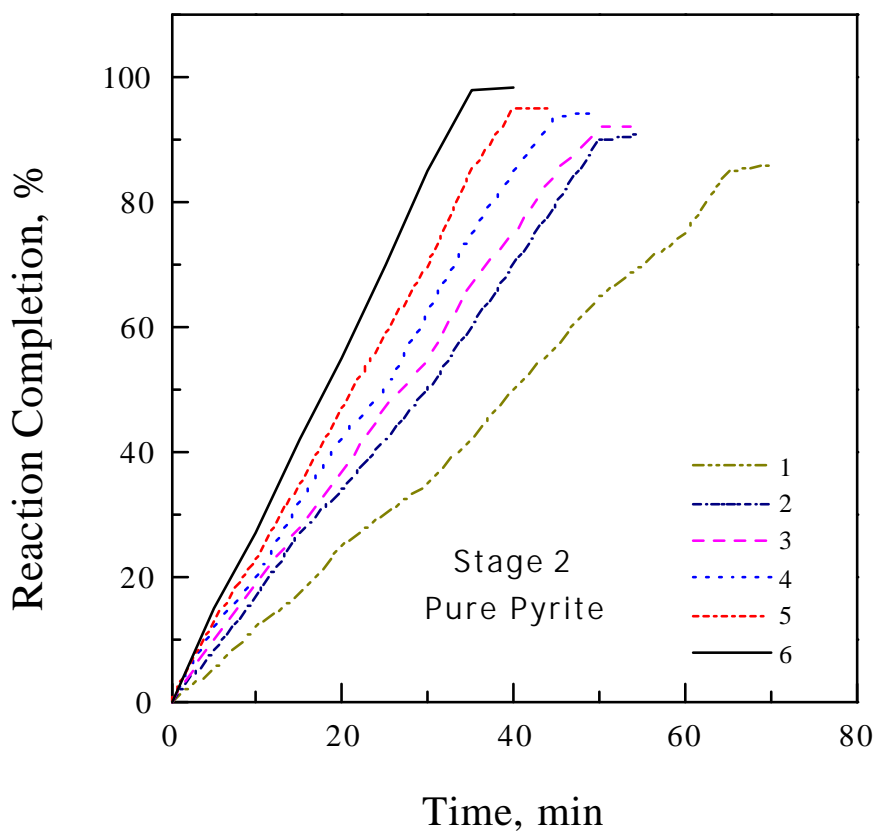

Figure 14. Effect of initial composition on the reaction rate for Reaction 2 at $1000^{\circ} \mathrm{C}$.

The stoichiometric ratio of FeS:CaO:C is $1-(1: 1: 1)$; 2-(1.1: 1.1: 1.1); 3-(1:1.1:2); 4(1:1.5:1.5); 5-(1:2:1.1); $6(1: 2: 2)$ 


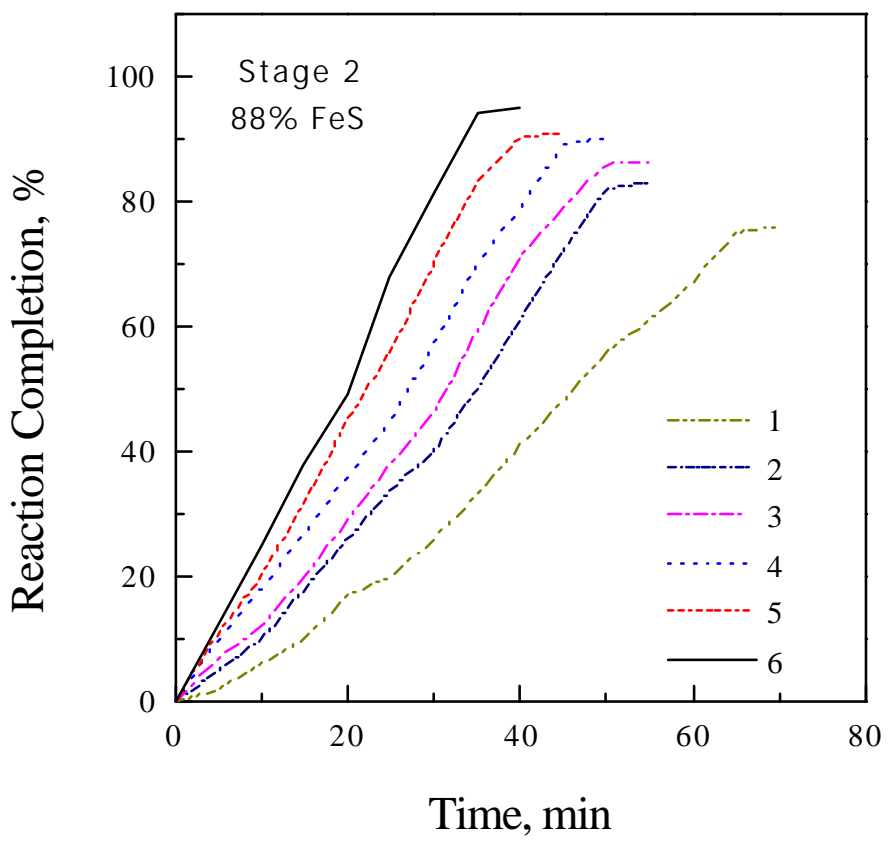

Figure 15. Effect of initial composition on the rate of reaction ( $88 \% \mathrm{FeS})$ (TGA)

The stoichiometric ratio of $\mathrm{FeS}: \mathrm{CaO}: \mathrm{C}$ is 1-(1:1:1); 2-(1.1: 1.1: 1.1); 3-(1:1.1:2); 4(1:1.5:1.5); 5-(1:2:1.1); 6 (1:2:2)

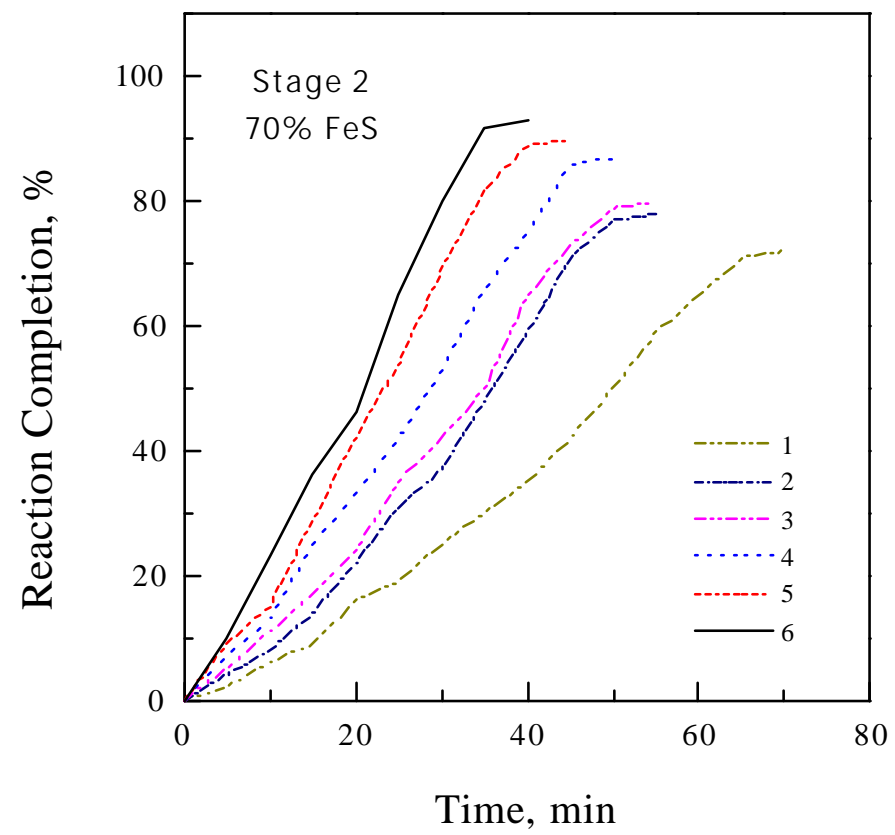

Figure 16. Effect of initial composition on the reaction rate of (\%70 FeS/CaO) (TGA) 
The stoichiometric ratio of $\mathrm{FeS}: \mathrm{CaO}: \mathrm{C}$ is 1-(1:1:1); 2-(1.1: 1.1: 1.1); 3-(1:1.1:2); 4-(1:1.5:1.5); 5-(1:2:1.1); 6-(1:2:2)

$\underline{\text { Muller Kuhne Reaction }}\left(\mathrm{CaS}+3 \mathrm{CaSO}_{4}=4 \mathrm{CaO}+4 \mathrm{SO}_{2}\right)$

The effect of temperature on the kinetics of Muller Kuhne reaction using pure reactants is shown in Figure 17. The reactant ratio is $\mathrm{CaS}: \mathrm{CaSO}_{4}=1: 3$. The results showed strong dependence of the reaction rate on temperature. At $1000^{\circ} \mathrm{C}$ the reaction reached $68 \%$ completion in more than two hours, while at $1150^{\circ} \mathrm{C} 95 \%$ completion was reached in 30 minutes. The activation energy was determined to be approximately $214.3 \mathrm{~kJ} / \mathrm{mol}$ (Figure 18).

When impure gypsum waste sample was used for the reation (Figure 19), the reaction reached $60 \%$ completion after two hours. The maximum reaction completion of $92 \%$ was achieved at $1150^{\circ} \mathrm{C}$ in 30 minutes. The activation energy was calculated to be $228.1 \mathrm{~kJ} / \mathrm{mol}$ (Figure 20).

Figures 21 and 22 show the effect of the reactant ratio $\mathrm{CaS}: \mathrm{CaSO}_{4}$ on the reaction rate at $1100^{\circ} \mathrm{C}$ using pure reactants and impure reactants, respectively. In both cases, excess amount of $\mathrm{CaSO}_{4}$ was found to increase the reaction rate as well as the maximum reaction completion. The reactant ratio of $\mathrm{CaS}: \mathrm{CaSO}_{4}=1: 6$ resulted in $98 \%$ reaction completion with pure reactants and $95 \%$ reaction completion with impure reactants at 25 minute reaction time.

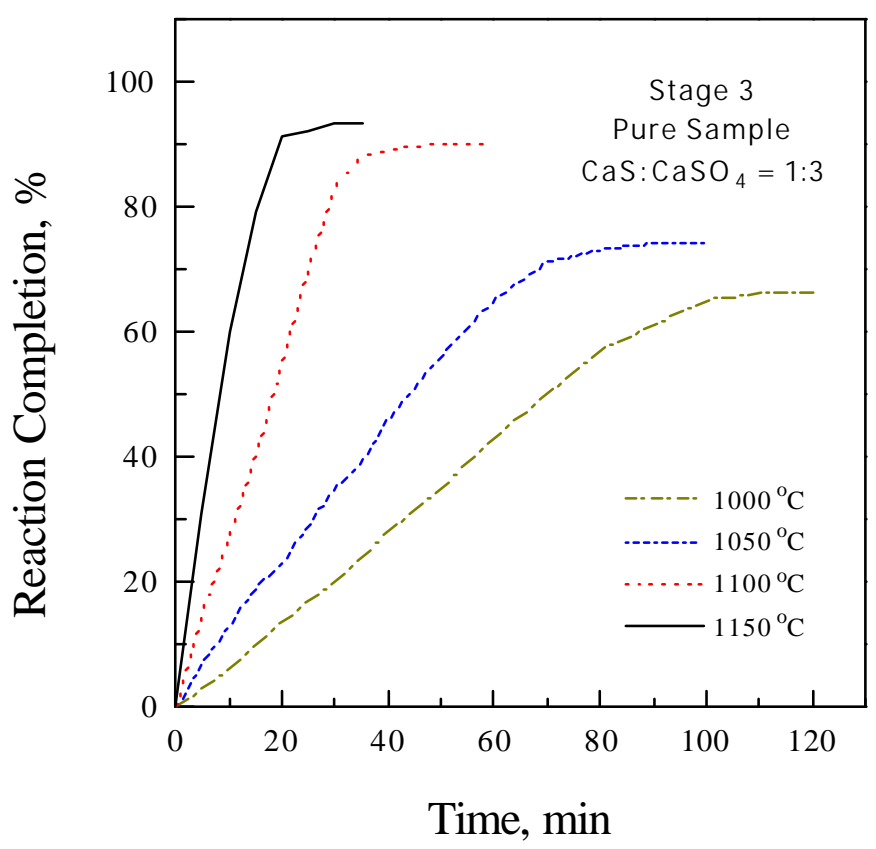

Figure 17. Effect of temperature on the rate of reaction of $3^{\text {rd }}$ stage. $\mathrm{CaS}: \mathrm{CaSO}_{4}=1: 3$ 


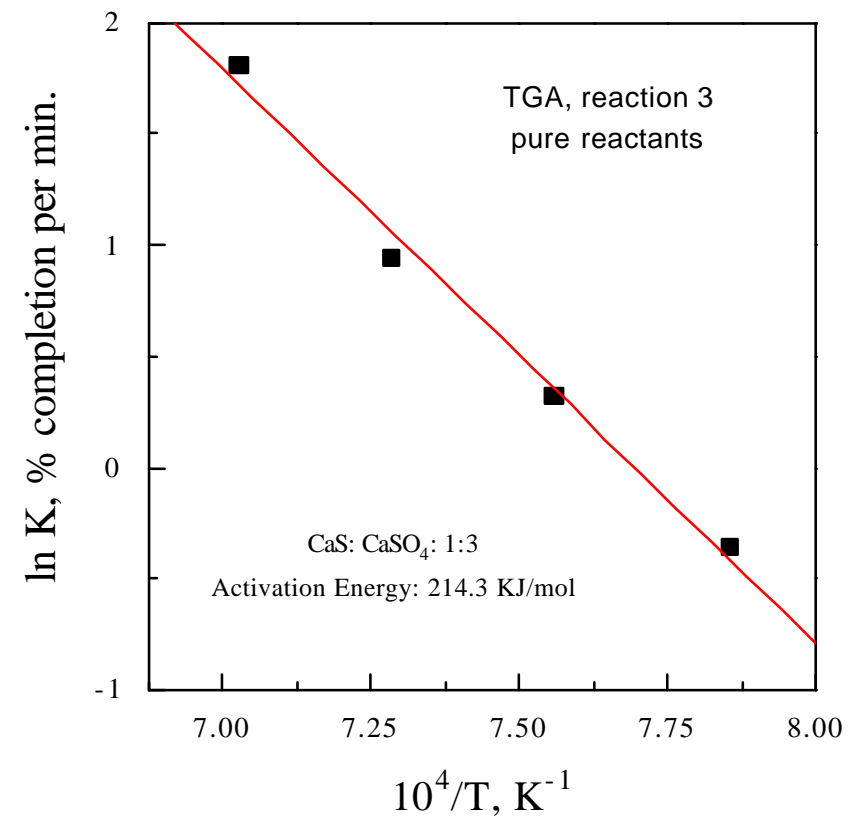

Figure 18. Activation Energy of Reaction 3 using pure reactants.

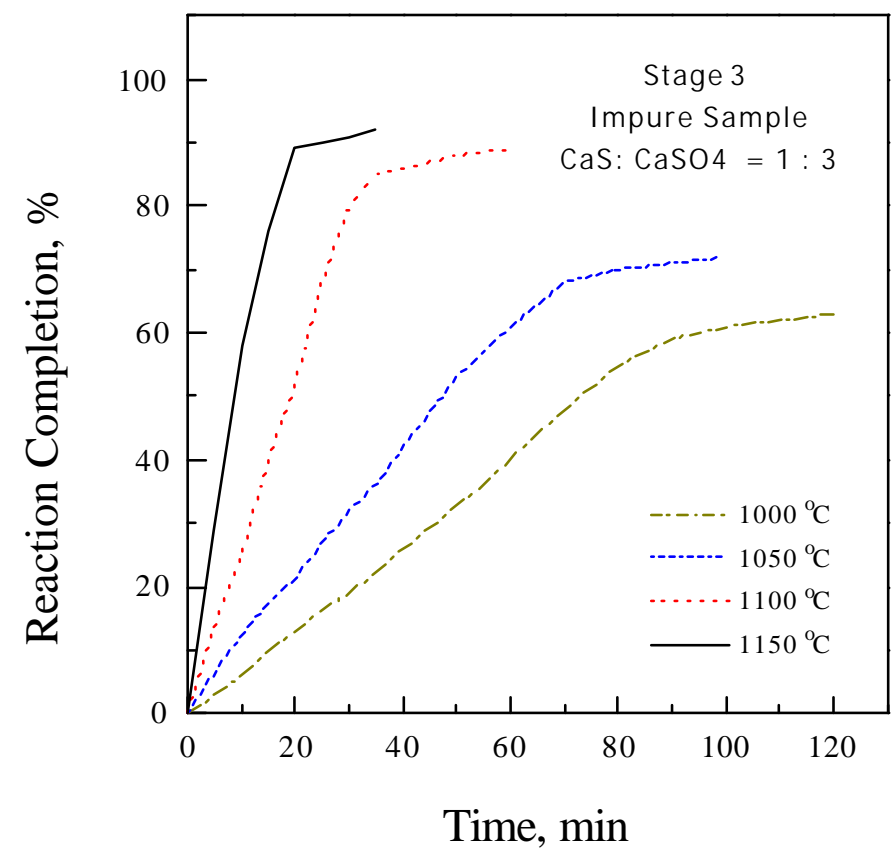

Figure 19. Effect of temperature on the rate of reaction of Reaction 3. CaS: $\mathrm{CaSO}_{4}=1: 3$ 


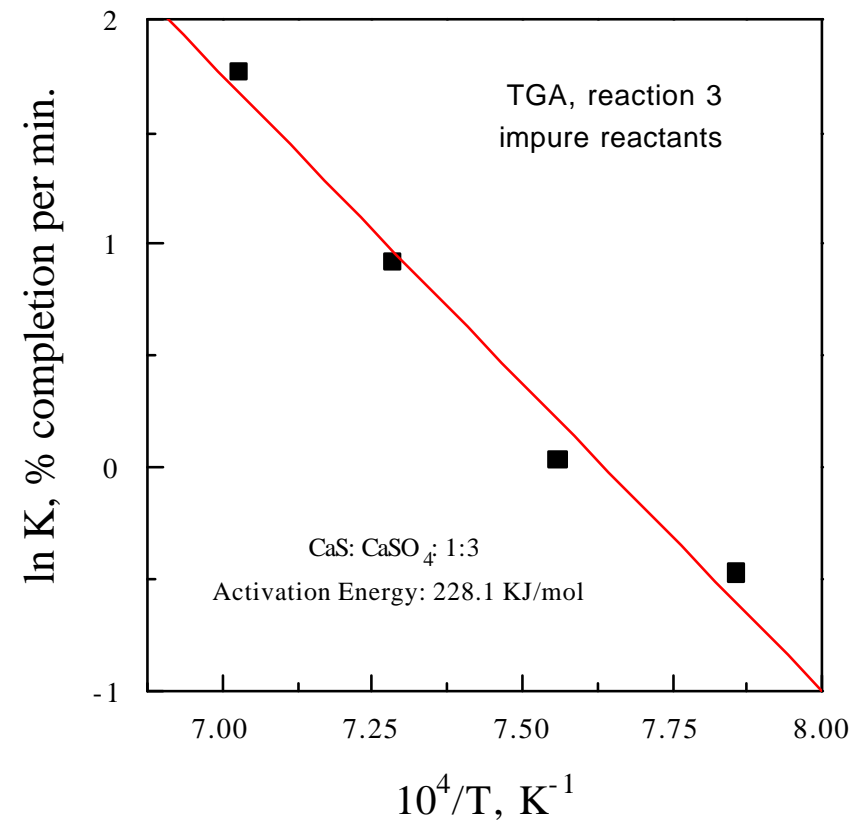

Figure 20. Activation Energy of Reaction 3 using impure reactants.

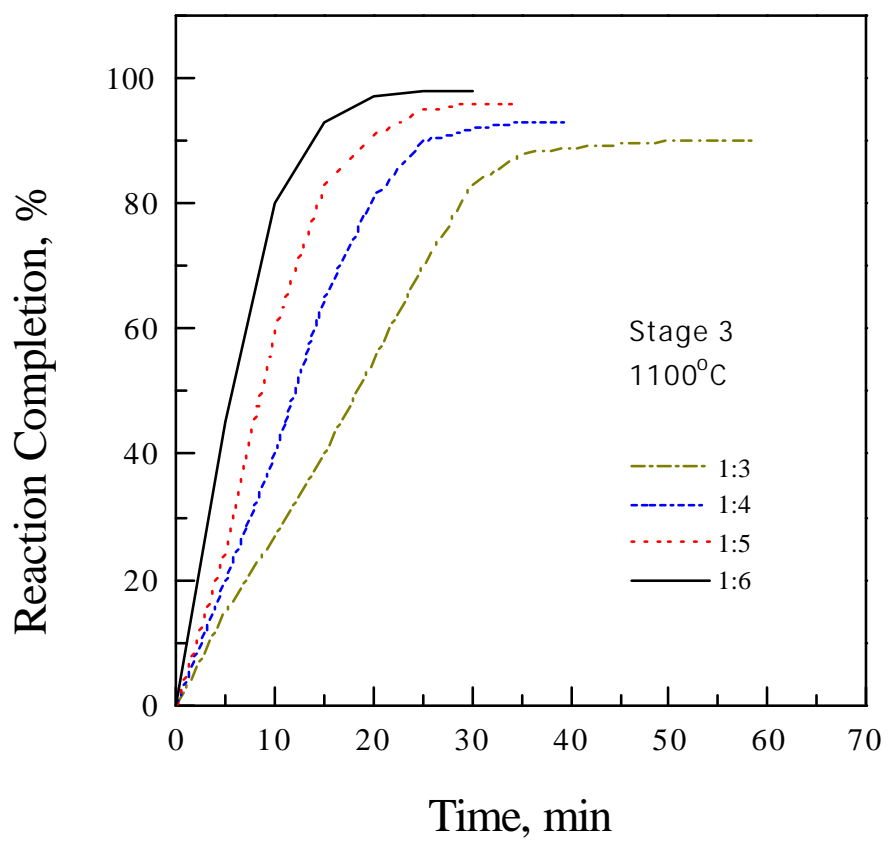

Figure 21. Effect of stoichiometric ratio $\mathrm{CaS}: \mathrm{CaSO}_{4}$ on the rate of Reaction 3 using pure reactants. 


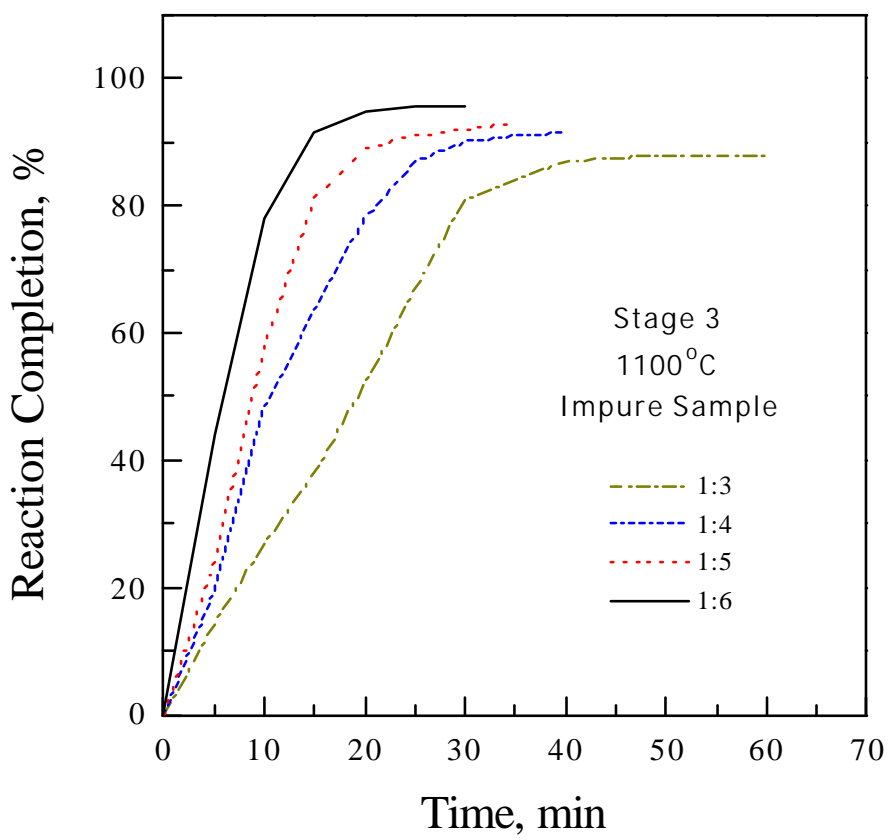

Figure 22. Effect of stoichiometric ratio $\mathrm{CaS}: \mathrm{CaSO}_{4}$ on the rate of Reaction 3 using impure reactants.

\section{Thermochemical Study Using Tube Furnace}

Based on the results and condition obtained using TGA, thermochemical reactions were performed in tube furnace to investigate the effect of temperature, particle size and reactant ratio on reaction kinetics. For each test, $\sim 20$ grams sample of reactant(s) was used.

Pyrite Decomposition $\left(\mathrm{FeS}_{2}=\mathrm{FeS}+\mathrm{S}\right.$. $)$

Figures 23 to 25 show the effect of temperature on the decomposition of pure mineral pyrite, $90 \%$ and $70 \%$ concentrated pyrite in the tube furnace, respectively. As can be seen from these figures, the temperature required to reach the same reaction completion was higher with the tube furnace than with TGA. For example, at $700^{\circ} \mathrm{C}$ the reaction reached $95 \%$ completion in 3 minutes with TGA but only $85 \%$ in one hour with the tube furnace. The maximum reaction rate was reached at a temperature of $850^{\circ} \mathrm{C}$ for all the three pyrite samples. This may be because that large amount of sample was used in tube furnace reaction ( 20 grams as compared to $40 \mathrm{mg}$ with TGA) and pyrrhotite formed masked the unreacted pyrite surface, preventing the further decomposition of the remaining pyrite. The activation energy was 91.7-96.4 kJ/mol (Figure 26). 


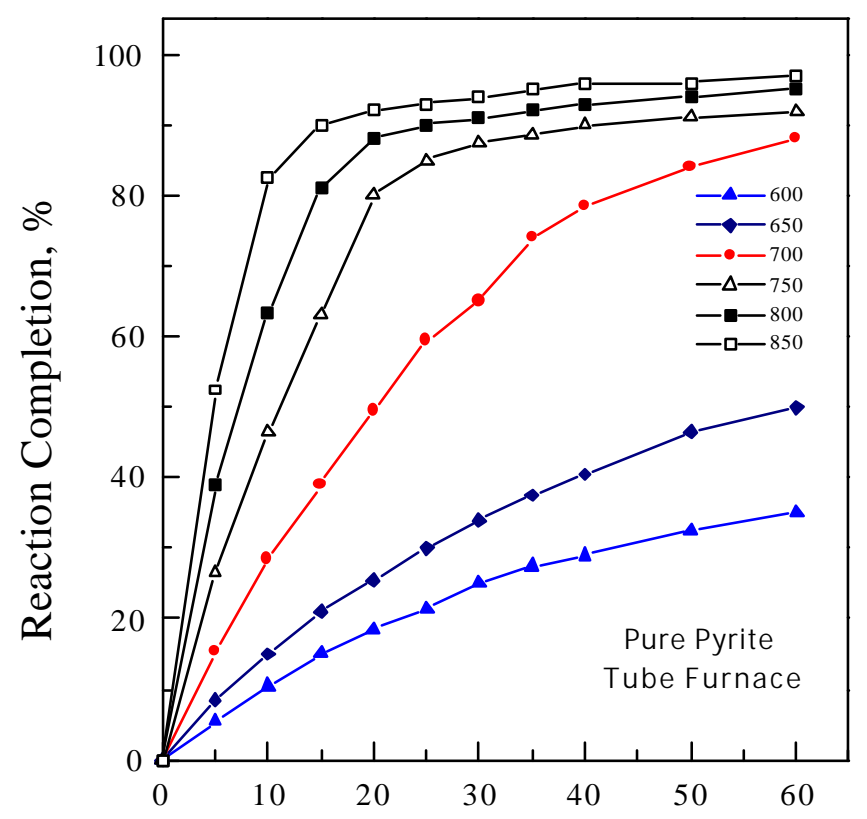

Time, min

Figure 23. Effect of temperature on the kinetics of Reaction 1 using pure pyrite in tube furnace (with $0.5 \mathrm{l} / \mathrm{min} \mathrm{N}_{2}$ gas).

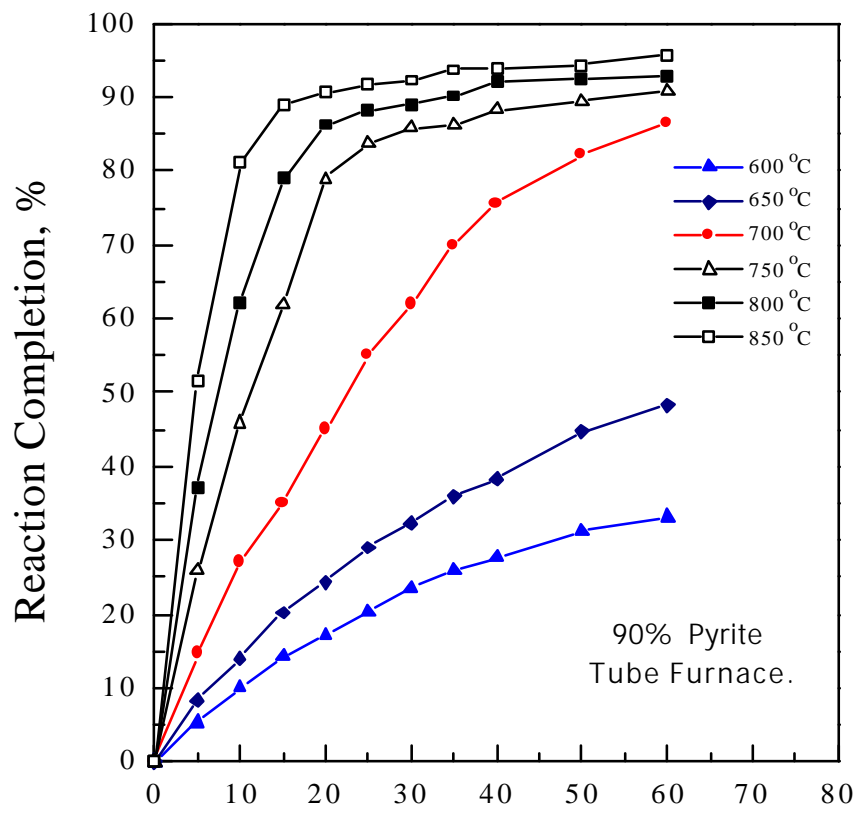

Time, $\min$

Figure 24. Effect of Temperature on reaction rate for Reaction 1 using $90 \%$ pyrite in tube furnace. (0.5 1/min $\mathrm{N}_{2}$ gas) 


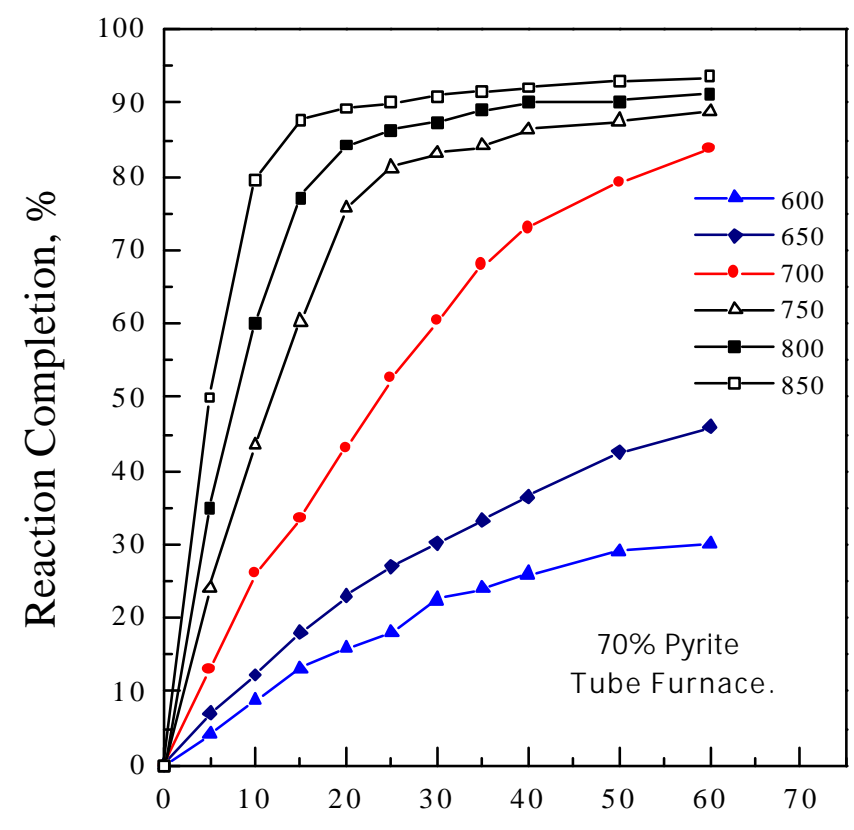

Time, $\min$

Figure 25. Effect of Temperature on reaction rate of Reaction 1 using $70 \%$ pyrite in tube furnace. (0.5 1/min N2 gas)

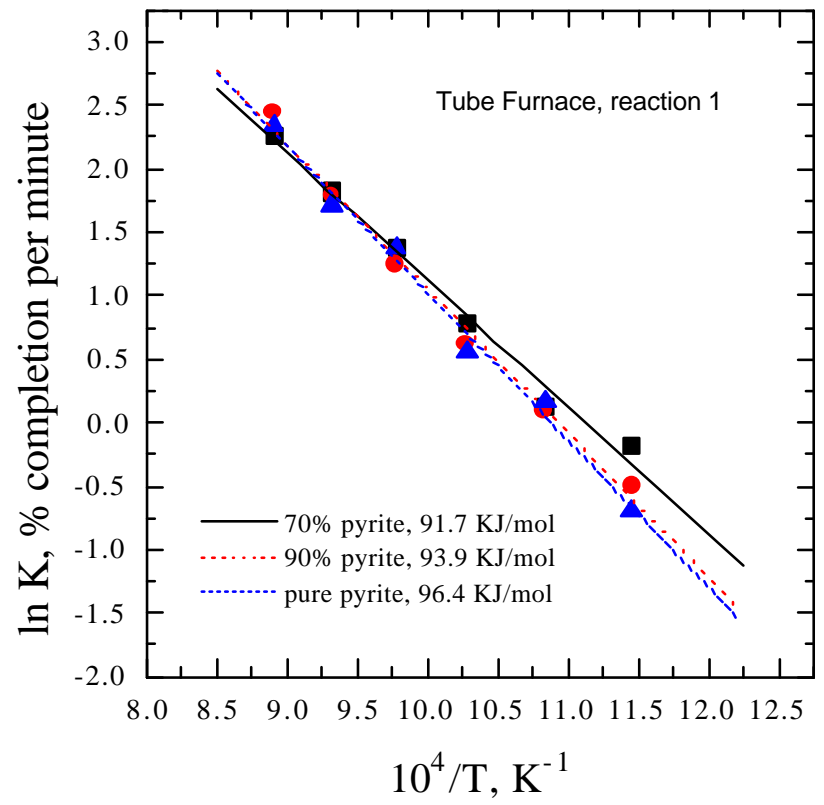

Figure 26. Activation Energy of Reaction 1 conducted using tube furnace.

Figures 27 to 29 show the effect of reactant particle size on the kinetics of Reaction 1 using pure, 90\%, and $70 \%$ pyrite, respectively, as reactant in the tube furnace. In all cases, decreasing the particle size 
increased the reaction rate and maximum completion. This is because the finer the particle size, the larger the surface area, and hence the faster the reaction rate.

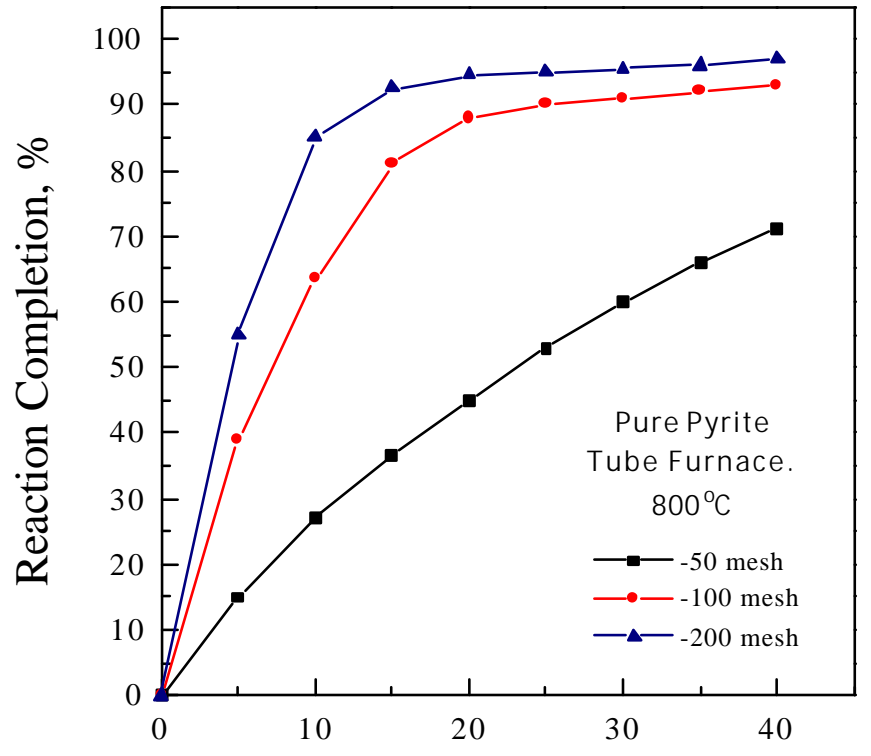

Time, $\min$

Figure 27. Effect of particle size on the rate of pyrite decomposition in tube furnace. $\left(800^{\circ} \mathrm{C}\right.$, $0.5 \mathrm{l} / \mathrm{min} \mathrm{N}_{2}$ )

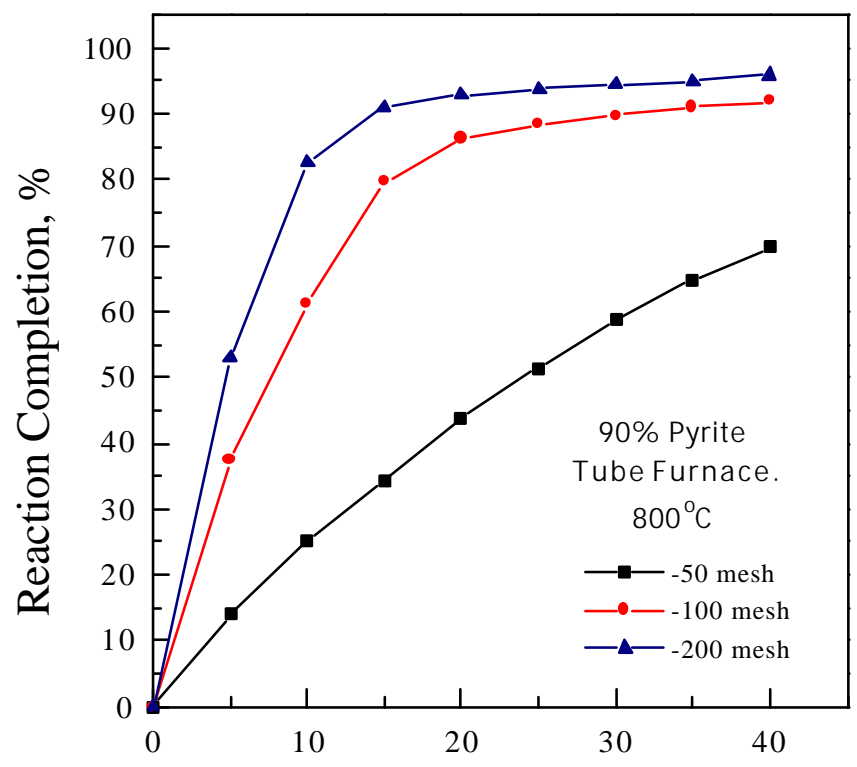

Time, $\min$

Figure 28. Effect of particle size on the rate of $90 \%$ pyrite decomposition in tube furnace. $\left(800^{\circ} \mathrm{C}, 0.51 / \mathrm{min}_{2}\right)$ 


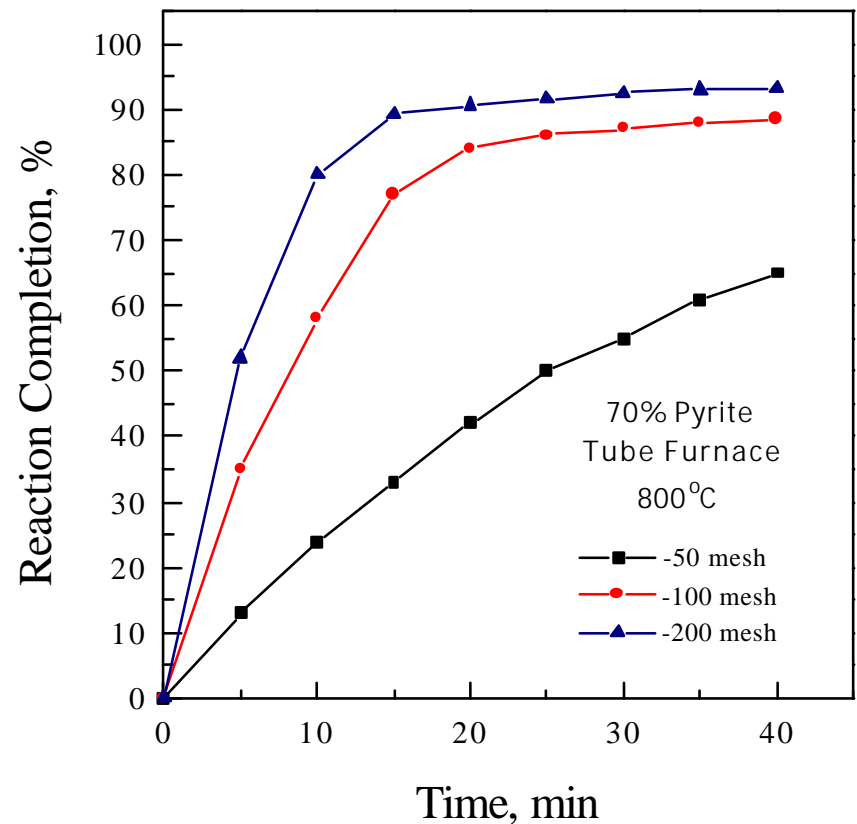

Figure 29. Effect of particle size on the rate of $70 \%$ pyrite decomposition in tube furnace. $\left(800^{\circ} \mathrm{C}, 0.51 / \mathrm{min}_{2}\right)$

For tube furnace reaction, the nitrogen flow rate had some effects on the degree of decomposition of pyrite to pyrrhotite, as shown in Figure 30. The nitrogen gas flow rate was maintained at $0.51 / \mathrm{min}$ in all the tests discussed below.

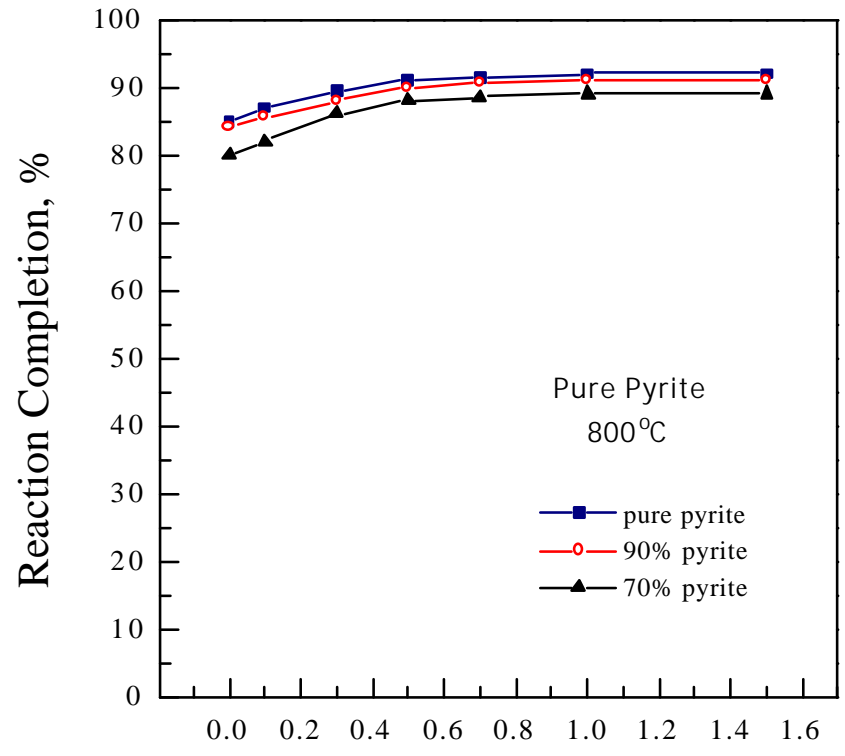

Gas Flow Rate, 1/min 
Figure 30. Effect of nitrogen gas flow rate on the rate of pyrite decomposition. $\left(30 \mathrm{~min}, 800^{\circ} \mathrm{C}\right)$

Pyrrhotite Reduction to $\operatorname{Iron}\left(\mathrm{FeS}+\mathrm{C}+\mathrm{CaO}=\mathrm{Fe}^{O}+\mathrm{CaS}+\mathrm{CO}.\right)$

Figure 31 shows the effect of temperature on the reaction kinetics of Reaction 2 in the tube furnace. The reactant ratio was $\mathrm{FeS}: \mathrm{CaO}: \mathrm{C}=1: 1.5: 1.5$. Similar to the TGA tests, the reaction rate increased with increasing temperature. The reaction reached $95 \%$ completion in 30 minutes at $1100^{\circ} \mathrm{C}$. The activation energy (Figure 32) calculated from the data in Figure 31, is lower than that determined from the TGA data.

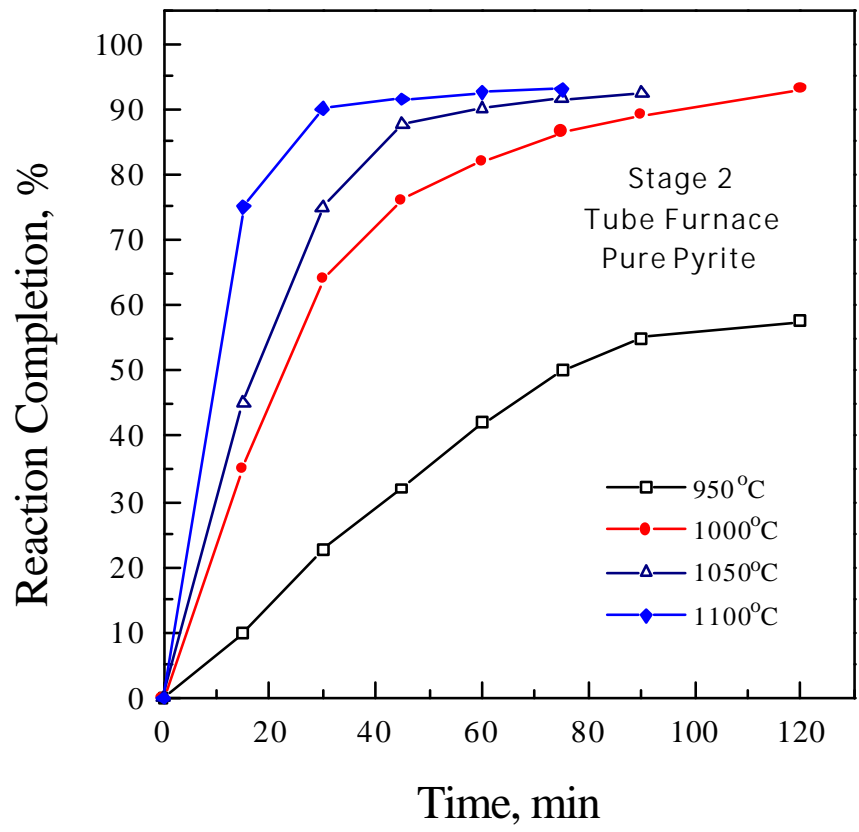

Figure 31. Effect of temperature on rate of Reaction 2 in tube furnace.

(FeS: $\mathrm{CaO}: \mathrm{C}=1: 1.5: 1.5, \mathrm{~N}_{2}$ gas flow $=0.5 \mathrm{l} / \mathrm{min}$ ) 


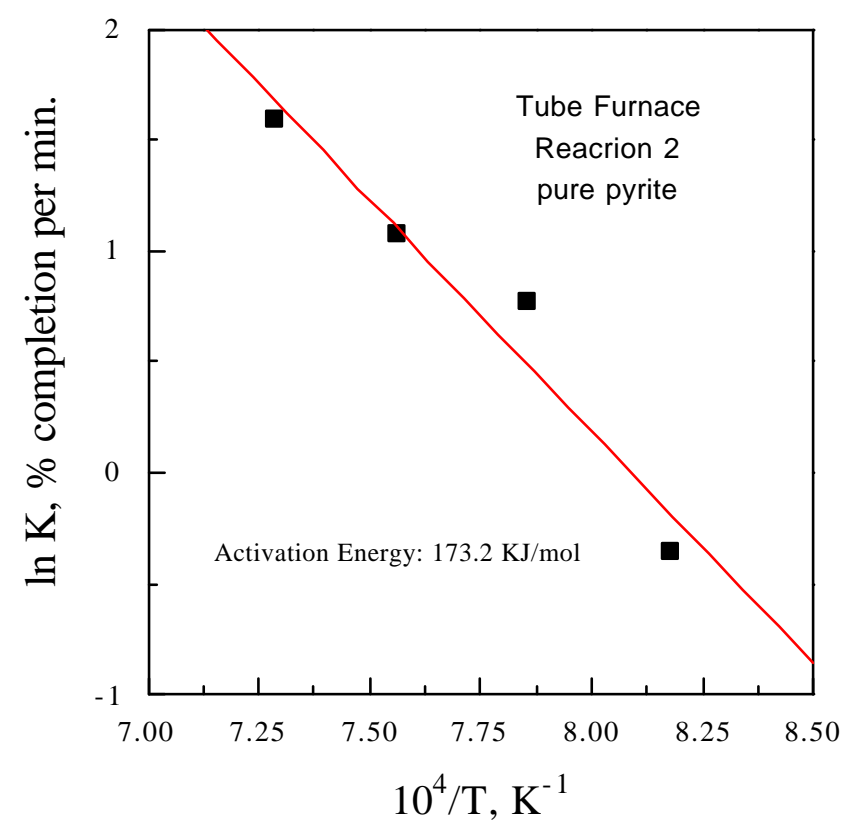

Figure 32. Activation Energy of Reaction 2 in tube furnace using pyrrhotite derived from pure pyrite. (FeS: $\mathrm{CaO}: \mathrm{C}=1: 1.5: 1.5, \mathrm{~N}_{2}$ gas flow $=0.5 \mathrm{l} / \mathrm{min}$ )

The effect of the stoichiometric ratio of the reactants on the kinetics of Reaction 2 using tube furnace is shown in Figure 33. The pyrrhotite was produced from pure pyrite and reaction temperature was $1000^{\circ} \mathrm{C}$. Similar to the TGA tests, excess $\mathrm{CaO}$ and reductant carbon increased the reaction rate and maximum reaction completion. The reactant ratio of FeS:CaO:C $=1: 2: 2$ provided $>92 \%$ reaction completion in less than an hour at $1000^{\circ} \mathrm{C}$.

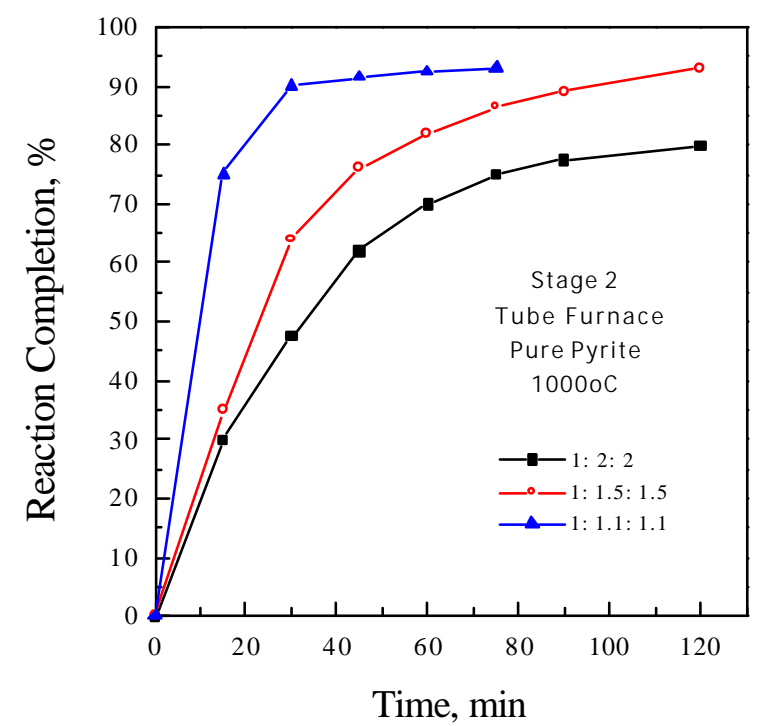

Figure 33. Effect of stoichiometric ratio of reactants FeS:CaO:C on the rate of Reaction 2 in tube furnace. (temperature $=1000^{\circ} \mathrm{C}, \mathrm{N}_{2}$ gas flow rate $=0.5 \mathrm{l} / \mathrm{min}$ ) 
$\underline{\text { Muller Kuhne Reaction }}\left(\mathrm{CaS}+3 \mathrm{CaSO}_{4}=4 \mathrm{CaO}+4 \mathrm{SO}_{2}\right)$

Figure 34 shows the effect of temperature on the kinetics of Reaction 3 in the tube furnace using pure reactants at the stoichiometric ratio of $\mathrm{CaS}: \mathrm{CaSO}=1: 3$. Similar to the TGA tests, the reaction rate increased with increasing reaction temperature. The reaction reached $>90 \%$ completion in $<70$ minutes at $1150^{\circ} \mathrm{C}$. The activation energy for Reaction 3 in the tube furnace was calculated to be 100.3 $\mathrm{kJ} / \mathrm{mol}$, as shown in Figure 35. Figures 36 and 37 show similar results obtained with impure reactants.

The effects of reactant ratio on the kinetics and reaction completion for Reaction 3 in tube furnace at $1100^{\circ} \mathrm{C}$ using pure and impure reactants are shown in Figures 38 and 39, respectively. Increasing the $\mathrm{CaS}: \mathrm{CaSO}_{4}$ ratio slightly decreased the reaction rate and reaction completion for this reaction. In the case of pure reactants, decreasing the reactant ratio $\mathrm{CaS}: \mathrm{CaSO}_{4}$ from 1:3 to 1:6 led to a slight increase in reaction completion from $\sim 90 \%$ to $95 \%$ in 75 minutes at $1150^{\circ} \mathrm{C}$. With the impure reactants the

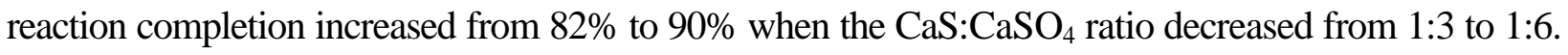

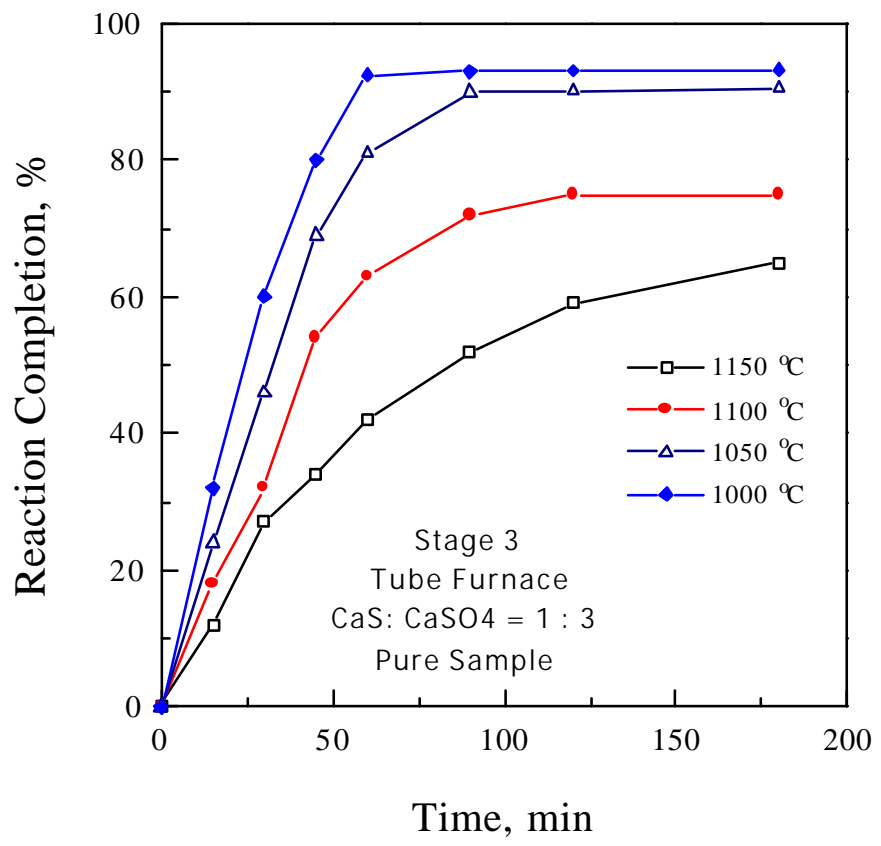

Figure 34. Effect of temperature on the reaction rate of Reaction 3 in tube furnace. (CaS: $\mathrm{CaSO}_{4}=1: 3$, pure reactants) 


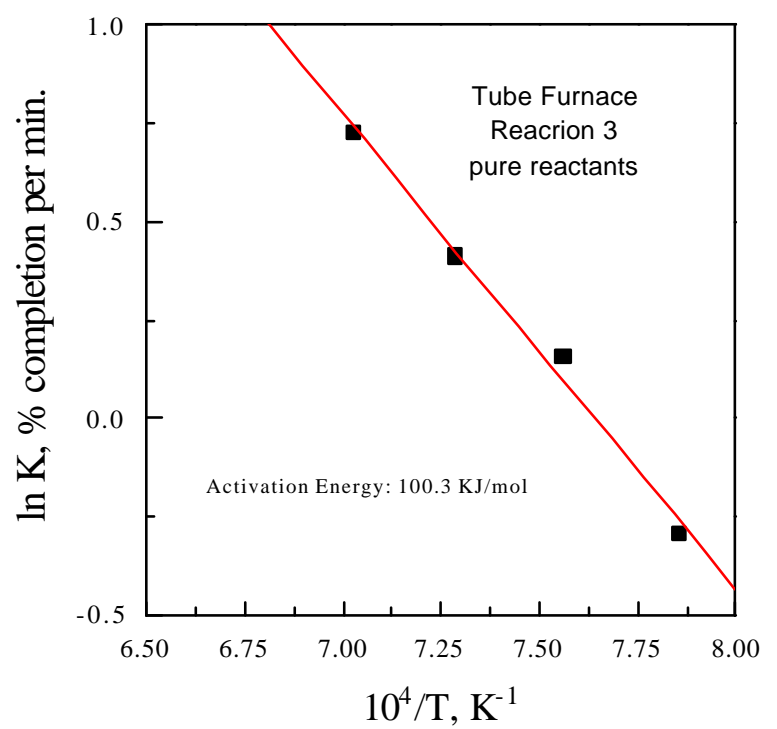

Figure 35. Activation Energy of Reaction 3 in tube furnace using pure reactants.

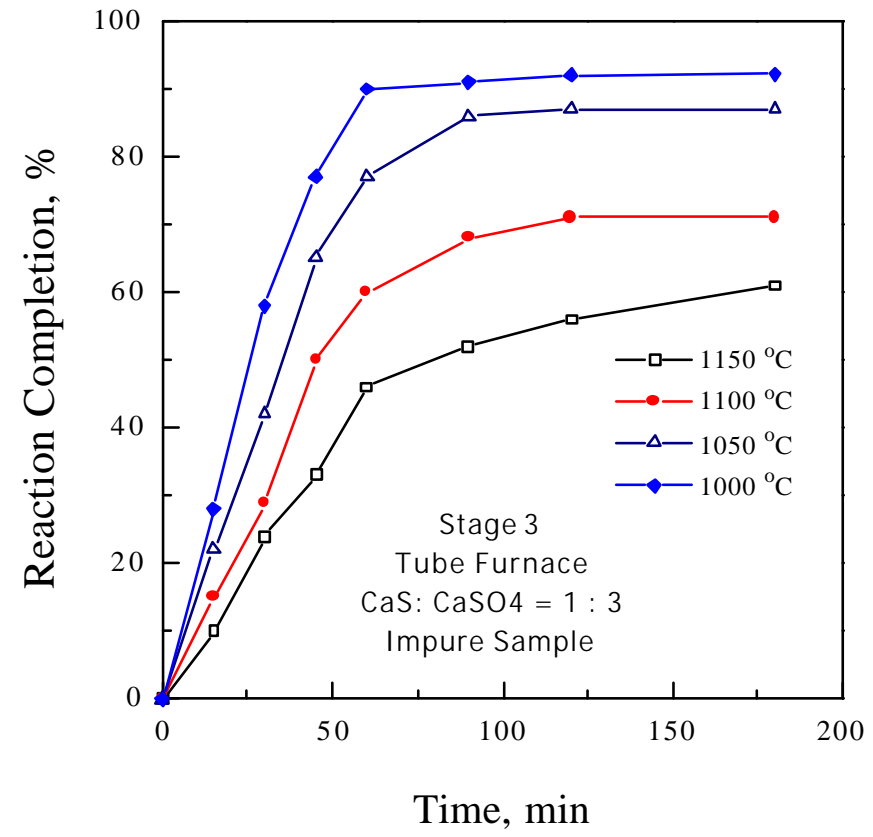

Figure 36. Effect of temperature on the reaction rate of Reaction 3 in tube furnace. (CaS: $\mathrm{CaSO}_{4}=1: 3$, impure reactants) 


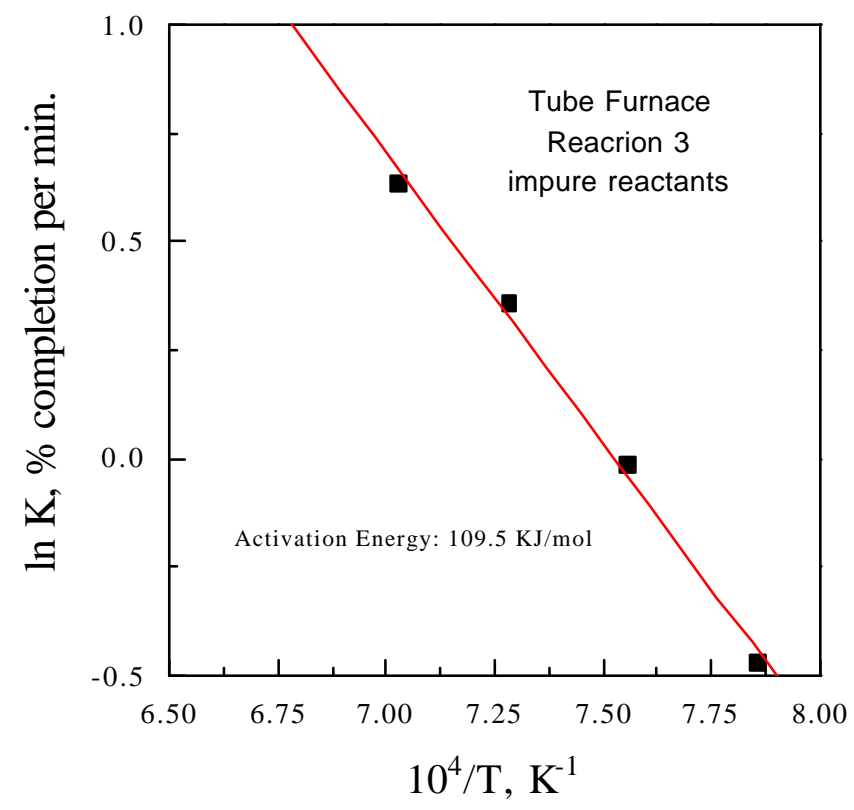

Figure 37. Activation Energy of Reaction 3 in tube furnace using impure reactants.

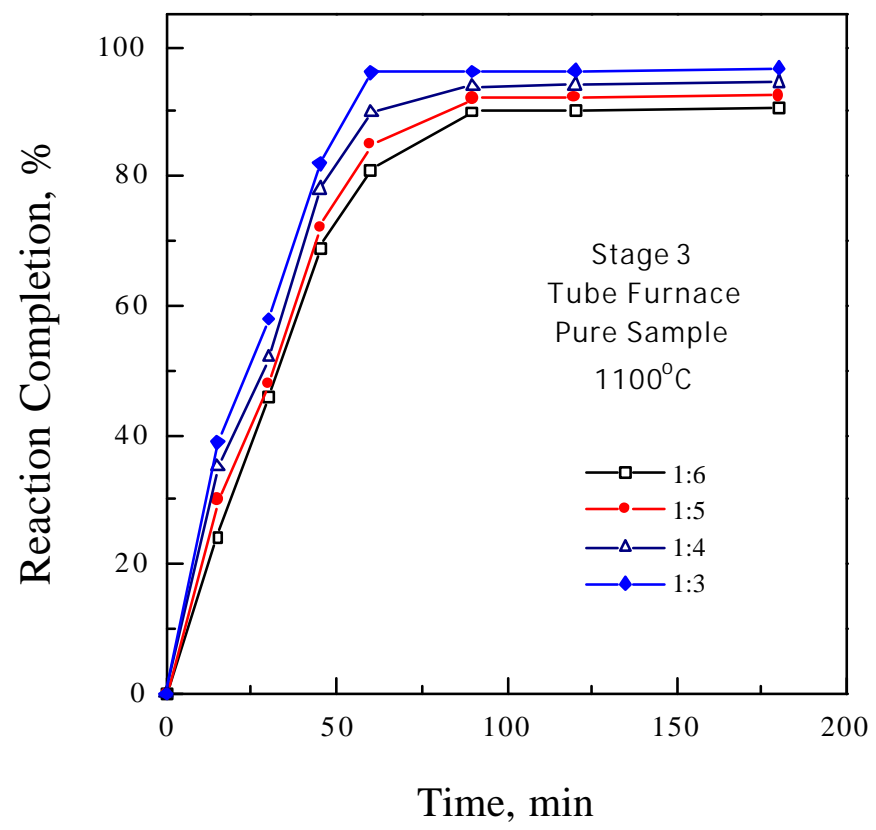

Figure 38. Effect of stoichiometric ratio $\mathrm{CaS}: \mathrm{CaSO}_{4}$ on the reaction rate of Reaction 3 in tube furnace. (temperature $=1100^{\circ} \mathrm{C}$, pure reactants) 


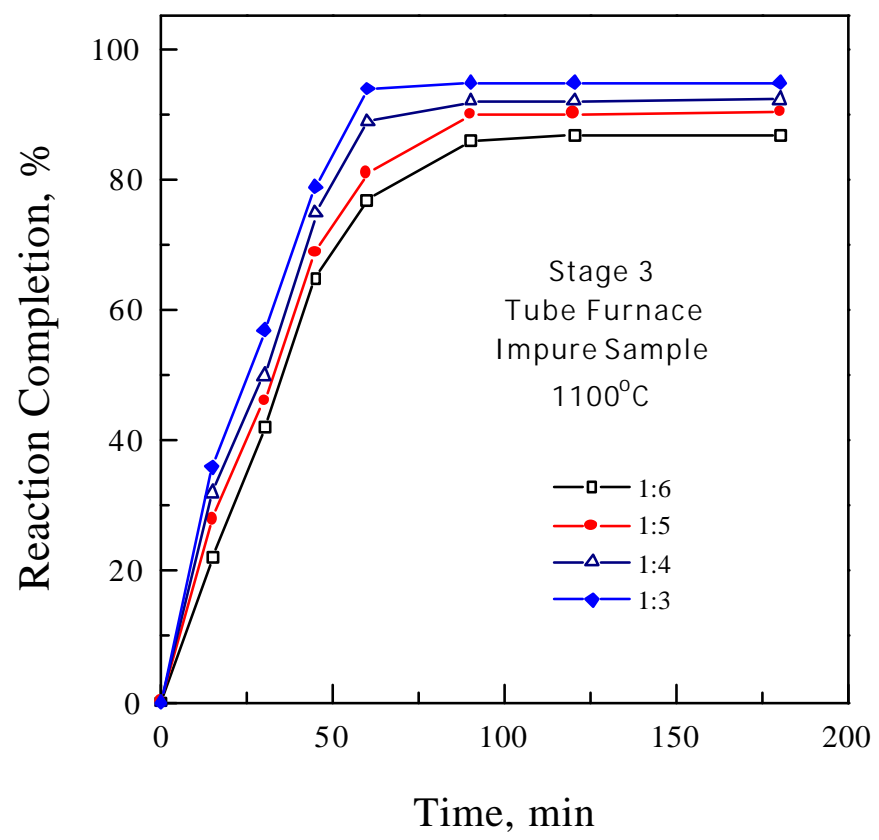

Figure 39. Effect of stoichiometric ratio $\mathrm{CaS}: \mathrm{CaSO}_{4}$ on the reaction rate of Reaction 3 in tube furnace. (temperature $=1100^{\circ} \mathrm{C}$, impure reactants)

\section{Separation of DRI from the Reaction 2 Product Mixture}

To effectively separate DRI from the mixture of the Reaction 2 products, experiments were conducted to study the effect of five parameters on the separation performance using Davis Tube magnetic separator. These parameters include current density, feed rate, solid content, tube stroke speed, and the temperature of Reaction 2. The purity of the DRI was measured by the total sulfur content in the processed DRI. The pyrrhotite used in Reaction 2 was derived from pure pyrite.

Figure 40 shows the effect of the current density on the purity of the DRI at different reactant ratio. As can be seen in the figure, the sulfur content in DRI was about $6 \%$ at $0.2 \mathrm{~A}$ current density. Increase in the current density increased the impurity level of the DRI. The excess lime and carbon in Reaction 2 was helpful in improving the DRI grade by magnetic separation. 


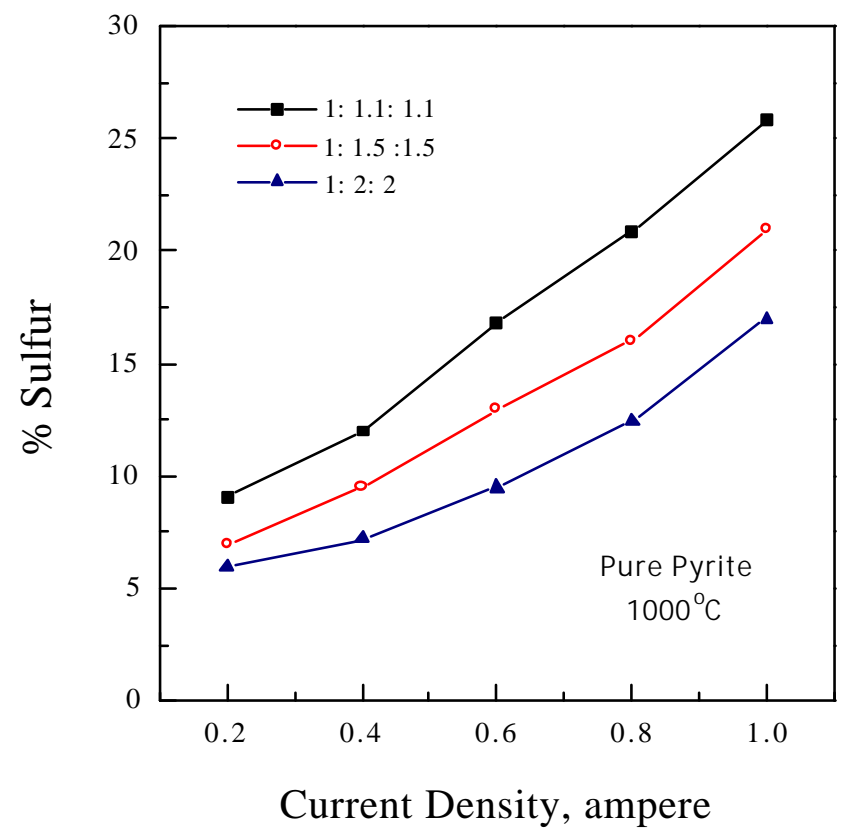

Figure 40. Effect of magnetic intensity on sulfur content in DRI product at different reactant ratio FeS:CaO:C at $1000^{\circ} \mathrm{C}$. (feed rate $=100 \mathrm{ml} / \mathrm{min}$, speed $=100$ stroke $/ \mathrm{min}$, solid content $=10 \%$ )

Figures 41-44 show the effect of feed rate, solid content, and stroke speed on the grade of DRI using magnetic separation, respectively. The optimal conditions for the separation are current density $=$ $0.2 \mathrm{~A}$, speed $=100$ stroke $/ \mathrm{min}$, solid content $=10 \%$, feed rate $=100 \mathrm{ml} / \mathrm{min}$, Reaction 2 temperature $=1000^{\circ} \mathrm{C}$, and reactant ratio $\mathrm{FeS}: \mathrm{CaO}: \mathrm{C}=1: 2: 2$. 


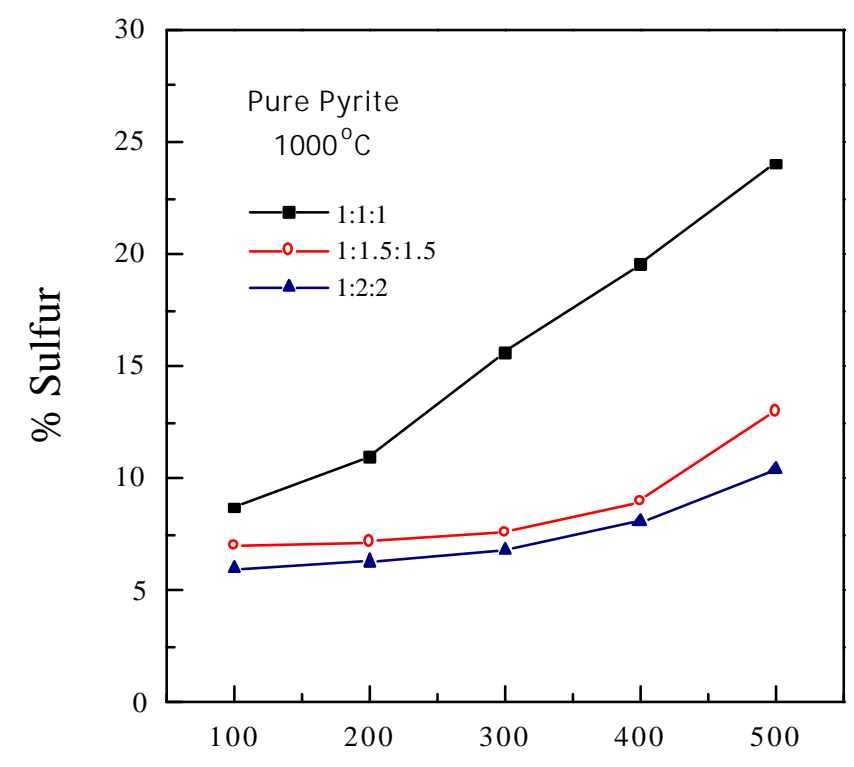

Feed Rate, $\mathrm{ml} / \mathrm{min}$

Figure 41. Effect of feed rate on sulfur content in DRI product at $1000^{\circ} \mathrm{C}$. (current intensity $=0.2 \mathrm{~A}$, speed $=100$ stroke $/ \mathrm{min}$, solid content $=10 \%$ )

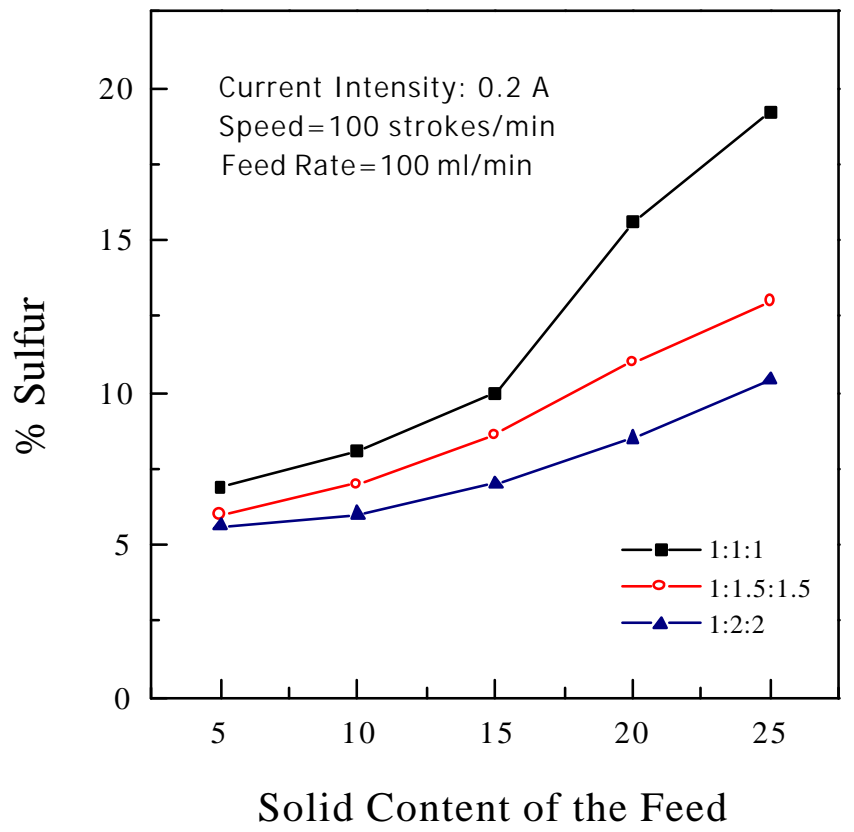

Figure 42. Effect of solid percentage on sulfur content in DRI product at $1000^{\circ} \mathrm{C}$. (current density $=$ $0.2 \mathrm{~A}$, speed $=100$ stroke $/ \mathrm{min}$, feed rate $=100 \mathrm{ml} / \mathrm{min}$ ) 


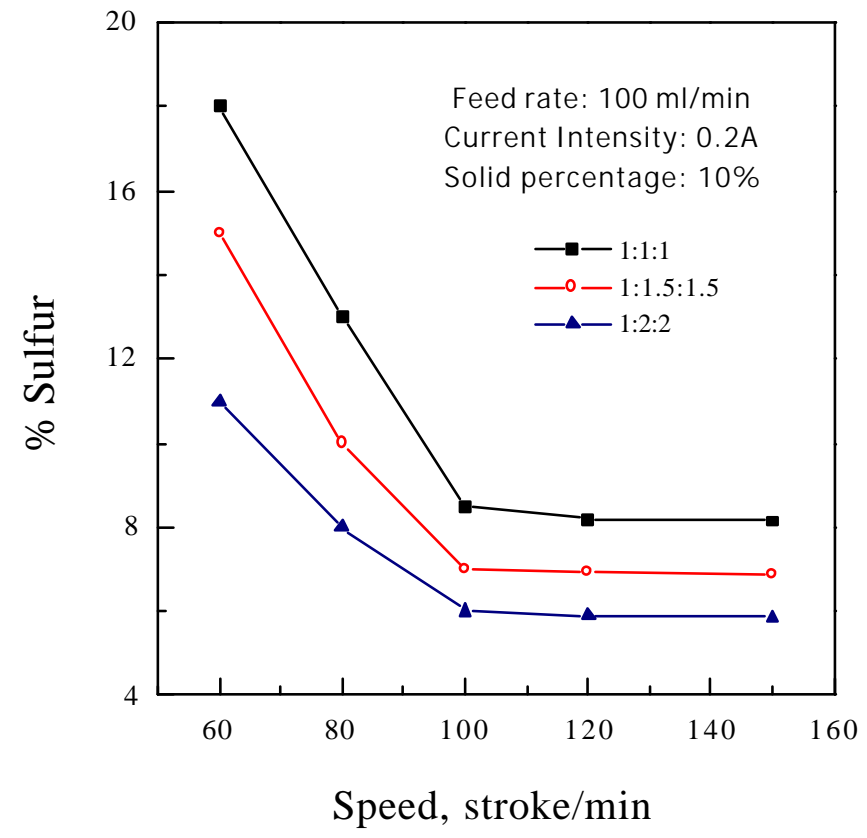

Figure 43. Effect of magnetic separator speed on sulfur content in DRI product at $1000^{\circ} \mathrm{C}$. (feed rate $=$ $100 \mathrm{ml} / \mathrm{min}$, current intensity $=0.2 \mathrm{~A}$, solid content $=10 \%$ )

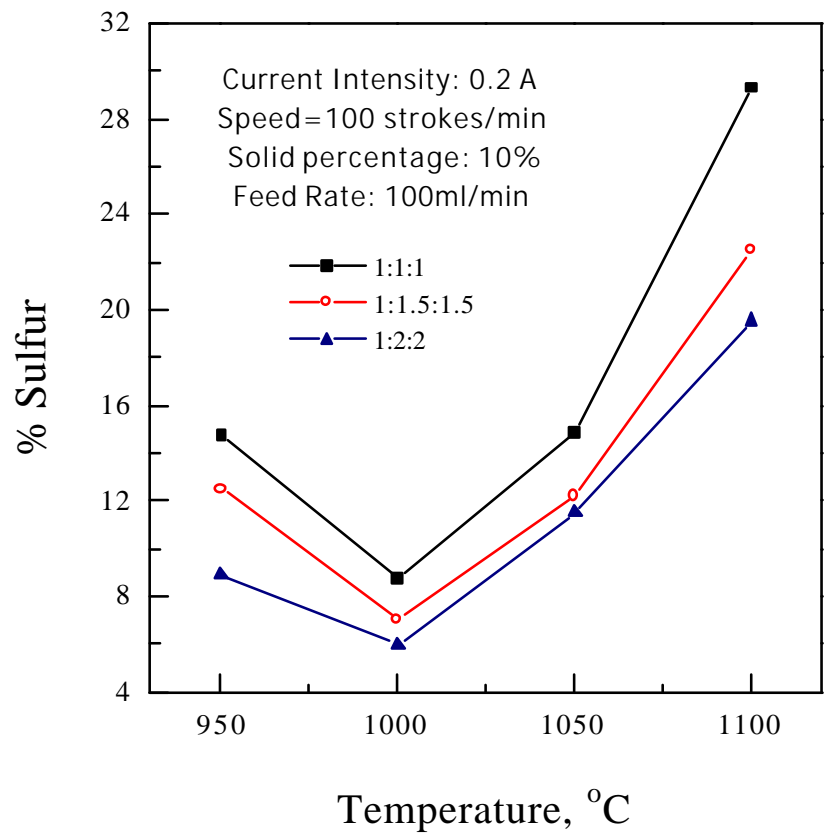

Figure 44. Effect of temperature on sulfur content in DRI product. (current density $=0.2 \mathrm{~A}$, speed $=$ 100 stroke $/ \mathrm{min}$, solid content $=10 \%$, feed rate $=100 \mathrm{ml} / \mathrm{min}$ ) 


\section{CONCLUSIONS}

Base on the results shown above, the following conclusions are made:

- The TGA and tube furnace study demonstrated that pyrite and gypsum wastes can be converted into iron, lime, and sulfur products using a thermochemical process. The overall reaction can be represented by:

$$
\mathrm{FeS}_{2}+3 \mathrm{CaSO}_{4}+\mathrm{C}+1 / 2 \mathrm{O}_{2}=\mathrm{Fe}^{o}+3 \mathrm{CaO}+4 \mathrm{SO}_{2}+\mathrm{S}+\mathrm{CO}_{2}
$$

- The overall reaction was accomplished in three consecutive steps that included pyrite decomposition to pyrrhotite, reduction of pyrrhotite to iron, and the Muller Kuhne reaction. Higher temperature increased the rate of all the thermochemical reactions involved.

- Pyrite can be effectively concentrated using the Falcon Concentrator, froth flotation, or dense medium separation. The Falcon Concentrator may be the most economical process.

- Thermochemical studies conducted in tube furnace show that the reaction kinetics for each thermochemical reaction was more dependent on temperature than on particle size and reactant ratio.

- Optimal reaction temperature for three individual reactions using tube furnace are 850, 1000 and $1150^{\circ} \mathrm{C}$, respectively and the optimal reaction time $20,30,50$ minutes, respectively.

- A stoichiometric excess of lime and carbon in initial mixtures enhanced the rate of iron production and increased the degree of reaction completion.

- The Muller-Kuhne process was effective in converting gypsum to lime that can be recycled to FGD processes. The excess of $\mathrm{CaSO}_{4}$ significantly enhanced the kinetics and degree of completion of the Muller Kuhne reaction.

- Finer particle size resulted in faster reaction kinetics in tube furnace reactions.

- DRI can be effectively separated from calcium sulfide using magnetic separation. The sulfur content of DRI was reduced to less than $6 \%$ in a single stage of magnetic separation. Use of multiple stages of magnetic separation can further lower the sulfur content in the DRI product.

\section{REFERENCES}

1. American Coal Ash Association (ACAA), 1992. "1991 Coal Combustion By-ProductProduction and Consumption." ACAA, Washington, DC, 1992.

2. U.S. Environmental Protection Agency (USEPA). "Wastes from the Combustion of Coal by Electric Utility Power Plants." EPA/530-SW-88-002, USEPA, Washington, DC, 1988.

3. General Accounting Office, 1977. "U.S. Coal Development - Promises, Uncertainties," Report to Congress, EMD-77-43, pp. 6.20,21 and 6.50,51. 
4. Feeley, T.J., III, Walsh, J.D., Gala, H.B., and Sniegicki, J.L., 1990. Proc. Of Processing and Utilization of High-Sulfur Coals III, edited by R. Markuszewski and T.D. Wheelock, Elsevier Science Publishers B.V., Amsterdam, pp. 99-107.

5. Shainberg, I., Sumner, M.E., Miller, W.P., Farina, M.P.W., Pavan, M.A., and Fey, M.V., 1989. Advances in Soil Science, edited By B.A. Stewart, Vol. 9, Springer-Verlag, New York, pp. 1111.

6. Wewerka, E.M., Williams, J.M., Wagner, P., 1982. The Use Of Multimedia Environmental Goals To Evaluate Potentially Hazardous Trace Elements From High Sulfur Coal Preparation Wastse, Los Alamos National Laboratory Report LA-9189 MS UC-901.

7. Wildeman, T.R., 1991. Gelogy in Coal Resource Utilization, edited by D.C. Peters, Techbooks, Fairfax, VA, p. 499.

8. Kleinmann, R.L.P., 1989. E\&MJ, July, p. 161.

9. Hite, D., Chern, W.S., and Fredrick, J.H., 1994. Proc. Of Eleventh Annual International Pittsburgh Coal Conference, Pittsburgh, PA, Sep. 12-16, pp.431-436.

10. Tao, D.P., Li, Y.Q., Richardson, P.E., and Yoon, R.-H., 1994. Coll. and Surf., 93:229-239.

11. Lowson, R.T., 1982. Chemical Rev., 82, p. 461.

12. Tao, D.P., Richardson, P.E., and Yoon, R.-H., 1993. Proc. of the International Conference on Processing and Utilization of High Sulfur Coals V, edited by B.K. Parekh and J.G. Groppo, Elsevier Science Publishers B.V., Amsterdam, pp. 219-236.

13. Attia, Y.A., 1993. Proc. of Processing and Utilization of High-Sulfur Coals V, edited by B.K. Parekh and J.G. Groppo, Elsevier Science Publishers B.V., Amsterdam, pp. 467-484.

14. Xuejun, L., 1991. Proc. of Processing and Utilization of High Sulfur Coals IV, edited by P.R. Dugan, D.R. Quigley and Y.A. Attia, Elsevier Science Publishers, Amsterdam, pp. 609-615.

15. Tavares, L.M. and Rubio J., 1991. Proc. of Processing and Utilization of High Sulfur Coals IV, edited by P.R. Dugan, D.R. Quigley and Y.A. Attia, Elsevier Science Publishers, Amsterdam, pp. 597-607.

16. Morizot, G., Morio, M., and Cecchin, T., 1985. Flotation of Sulfide Minerals, ed. by K.S.E. Forssberg, Elsevier, pp. 293-316.

17. Honaker, R.Q., Paul, B.C., Wang, D., and Ho, K., 1995. High Efficiency Coal Preparation: an International Symposium, SME-AIME, Littleton, pp. 69-78.

18. Honaker, R.Q., Mohanty, M.K., Wang, D., and Ho, K., 1996. Proc. Of Thirteenth Annual International Pittsburgh Coal Conference, Pittsburgh, PA, Sep. 3-7, pp. 1375-80.

19. Monteiro, J.L.F., 1981. Can. J. Chem. Eng., 59:511-516.

20. Mehta, B.R. and O'Kane, P.T., 1968. CIM Bulletin, July, pp. 836-846.

21. Watkinson, A.P., Germain, C., 1972. Can. Metall. Q., 11(3), pp.535-547.

22. Jha, A. and Grieveson, P., 1992. Scan. J. Metall., 21, pp. 50-62.

23. Barker, L.M., inventor, Phelps Dodge Corp. Assignee, 1965. "Recovery of mineral values from ore," U.S. Patent 3,168,398.

24. Won, S. and Sohn, H.Y., 1985. Metall. Trans., Vol. 16 B.

25. Prasad, P.M. and Mankhand, T.R., 1983. Advances in Sulfide Smelting, Vol. 1: Basic Principles, edited by H.Y. Sohn, D.B. George, and A.D. Zunkel, Warrendale, PA, The Metallurgical Society of AIME, pp. 371-392.

26. Shan, I.D. and Ruzzi, P.L., 1978. Metallurgical Transations, 9B, pp. 247-253. 
27. Habashi, F. and Dugdale, R., 1973. Metallurgical Transaction, Vol. 4, pp. 1865-71.

28. Kerby, R.C., 1973. "Direct reduction of iron and nickel sulfides by $\mathrm{CaO}$ and $\mathrm{CO}$ and subsequent recovery of elemental sulfur," Canadian Mines IR 73-47.

29. Sohn, H.Y. and Rajamani, K., 1976. "Analysis of sulfur fixation in the treatment of sulfide ore/lime mixture," paper presented at the $105^{\text {th }}$ Annual AME Meeting at Las Vegas, NV, Feb. 22-26.

30. Ganguly, N.D. and Bannerjee, A.C., 1973. Ind. Eng. Chem. Process Design and Development, Vol. 12, No. 1.

31. Wieczorek-Ciurowa, K., 1992. J. Therm. Anal., 38(3), pp. 523-530.

32. Elcor, 1968. Sulfur, No. 79, Nov./Dec., pp. 29-30.

33. Wheelock, T.D. and Boylan, D.R., 1968. Chem. Eng. Prog., 64(11): 87-92.

34. Erb, T., Huff, B., Shay, D., and Kozlowski, A., 1997. The Search for a Match between Utility Gypsum Waste and Coal Mine Pyrite Waste, unpublished.

35. Morris , A.E., Flynn, H., Carter, D., 1990. Using the UMR STEPSOL package, Version 4.0, GMTCP, University of Missouri at Rolla, Rolla, MO.

36. Nordman, B., 1994. "Paper efficiency: energy and beyond," presented to Energy Efficient Office Technology, October, $1994 . \quad$ Posted on website: http://eande.lbl.gov/EAP/BEA/Bnordman/beyond.html.

37. "Iron Age scrap price bulletin," New Steel, July, 1998, p. 54-56.

38. "Chemical Price," Chemical Market Reporter, December, 1997, p. 50-57.

39. Quotation from Ash Grove Cement Company, Little Rock, Arkansas, August, 1998.

40. Mark, H.F., Othmer, D.F., Overberger, C.G., and Seaborg, G.T., 1978. Kirk-Othmer Encyclopedia of Chemical Technology, Vol. 14, John Wiley and Sons.

41. Mark, H.F., Othmer, D.F., Overberger, C.G., and Seaborg, G.T., 1978. Kirk-Othmer Encyclopedia of Chemical Technology, Vol. 10, John Wiley and Sons.

42. Estep, J.W., McBride, G.T., Jr., and West J.R., 1962. Advances in Petroleum Chemistry and Refining, Vol 6, edited by J.J. McKetta, Jr., Interscience Publishers, a division of John Wiley \&Sons, Inc., New York, p361.

43. The Florida Institute of Phosphate Research, 1995. Strategic Initiatives and Applied Research Priorties, 1855 West Main Street, Bartow, Florida 33830. 